\title{
Towards a Trait Model of Video Game Preferences
}

\author{
Gustavo Fortes Tondello ${ }^{1,3,6, *}$, Deltcho Valtchanov ${ }^{6}$, Adrian Reetz $^{2,6}$, Rina R. Wehbe ${ }^{1,3,6}$, \\ Rita Orji ${ }^{1,6,7}$, Lennart E. Nacke $e^{1,3,4,5,6}$ \\ gustavo@tondello.com* ${ }^{*}$ dvaltchanov@uwaterloo.ca, adrian.reetz@uwaterloo.ca, \\ rina.wehbe@uwaterloo.ca, rita.orji@dal.ca, lennart.nacke@acm.org \\ ${ }^{1}$ HCI Games Group, University of Waterloo \\ ${ }^{2}$ Touch Lab, University of Waterloo \\ ${ }^{3}$ Cheriton School of Computer Science, University of Waterloo \\ ${ }^{4}$ Department of Drama and Speech Communication, University of Waterloo \\ ${ }^{5}$ Stratford Campus, University of Waterloo \\ ${ }^{6}$ The Games Institute, University of Waterloo \\ 200 University Avenue West, Waterloo, ON, Canada N2L 3G1 \\ ${ }^{7}$ Department of Computer Science, Dalhousie University \\ Halifax, NS, Canada \\ * contact author
}

This is an Accepted Manuscript of an article published by Taylor \& Francis in the International Journal of Human-Computer Interaction on 19 April 2018, available online:

http://www.tandfonline.com/10.1080/10447318.2018.1461765.

To cite this article: Gustavo Fortes Tondello, Deltcho Valtchanov, Adrian Reetz, Rina R. Wehbe, Rita

Orji \& Lennart E. Nacke (2018): Towards a Trait Model of Video Game Preferences, International Journal of Human-Computer Interaction, DOI: 10.1080/10447318.2018.1461765 


\section{ABSTRACT}

Typologies for understanding players' preferences towards different gameplay styles have gained popularity in research. However, attempts to model players' preferences are based on type models instead of trait models, contrary to the latest personality research. One such model, BrainHex, was designed as an interim model to enable investigations towards a definitive player trait model. However, it lacks empirical validation in support of its psychometric properties. The present work analysed a dataset with over 50,000 respondents to devise a player traits model based off the BrainHex scale. Results indicate three player traits: action, esthetic, and goal orientation. Furthermore, we analysed the games listed by participants as examples of what they enjoy, to understand which factors influence player preferences. Results illustrate that the emergent player traits and participants' genders and attitudes towards story can partially explain player preferences towards certain games. Finally, we present the implications towards a definitive player traits model.

\section{Keywords}

Games; Games User Research; BrainHex; Player Typology; Player Traits; Motivation; Scale Design. 


\section{INTRODUCTION}

Understanding personality types can be helpful in many scenarios, for example, finding a satisfactory occupation, managing and guiding employees, or developing effective teaching methods. In games, player types are similarly helpful. Player types support game designers and researchers in understanding player behaviour; thus, providing a foundation upon which they can study player experience, motivational factors of digital games, and effective learning strategies. Classifying players into different types can also be an important design tool for games and gamified applications (Bakkes, Tan, \& Pisan, 2012; Busch et al., 2015; Orji, Mandryk, Vassileva, \& Gerling, 2013). Therefore, several authors have proposed different models of player types or gaming motivations (Hamari \& Tuunanen, 2014). However, some of these models are only theoretical and lack empirical validation, whereas others are limited to specific game genres or are not publicly available.

BrainHex (Nacke, Bateman, \& Mandryk, 2014) is a player typology that captures player preferences towards a broad range of games and is intended to help game designers and researchers understand player preferences towards different games, play styles, and gaming systems. However, it is presented as an interim model, which exists primarily to enable further investigations towards a more robust player trait model. As suggested by Nacke et al. (2014), the BrainHex data should be further examined with the goal of finding statistical evidence for significant patterns of play. Their results posit two potential trait models, which warrant further investigation. The first possibility is a 4-trait model: (1) preference for visceral play (i.e., fight-or-flight rewards); (2) preference for esthetic experience; (3) goal orientation or obsessive play; and (4) preference for experiential play. On the other hand, the second possibility is a simplified 2-trait model: (1) preference for visceral versus esthetic play and (2) degree of goal orientation. Furthermore, Busch et al. (2016) conducted an initial validation of the psychometric properties of the BrainHex scale suggested by Nacke and colleagues (2014) with a new dataset and found that improvements are required. 
In this paper, we present the results of two studies that we conducted using Nacke et al.'s (2014) original dataset of more than 50,000 participants with the goal of identifying patterns of play that can potentially lead to the development of a robust player trait model.

In the first study, we analysed data from the BrainHex survey using Structural Equation Modeling to evaluate how well this interim scale represents the underlying construct that it intends to measure (i.e., player preferences for different styles of play). Our results demonstrate that the scale was not able to measure seven different playing styles as originally suggested with sufficient discrimination between them. Instead, the data suggests only three distinguishable playing motivations: (1) action orientation (represented by the conqueror and daredevil archetypes); (2) esthetic orientation (represented by the socializer and seeker archetypes); and (3) goal orientation (represented by the mastermind, achiever, and survivor archetypes).

The first study revealed findings regarding identified patterns of play. However, these findings are based on participants' self-reported answers to a survey. Therefore, they need to be validated by comparing them with players' real inclination toward different games. Nacke et al.'s (2014) BrainHex survey includes data about the games that exemplify what participants enjoy about games, such as Super Mario or World of Warcraft. Thus, we used them to test whether participants' scores on the three player traits identified in the first study can explain their preferences for different games. Hence, in the second study, we analysed the games that participants cited as examples of what they enjoy with the goal of understanding the patterns of play that emerge from these data and compared them with the patterns identified in the first study. Consequently, the second study presents results of a data analysis of the games that participants listed as examples of what they enjoy. First, we describe how we devised a method for cleaning and clustering game names from free-entry text into their corresponding game franchise or series name. Our method allowed us to collect information about 3,000 unique games from over 150,000 free-text entries in response to the question "Name three games that exemplify what you enjoy about games" (each participant could list up to three games). Next, we used a principal component analysis to group the 26 most cited game franchises 
into 14 groups based on their co-occurrence. We define co-occurrence as participant-identified games that were frequently cited together. Thus, we evaluated the similarity of player preferences for games with a higher accuracy when compared to simply grouping them by genre. Next, we looked at the 14 game groups and analysed participants' scores on the three traits identified on the first study, as well as gender and attitude towards story in games, to understand why they like each game and how the player trait model from the first study can help us understand these preferences.

Additionally, the set of the 26 game franchises we analysed is representative of the most popular commercial games at the time because it includes some of the most successful franchises in digital game history, such as Final Fantasy and Pokémon, each one having sold millions of copies or subscriptions worldwide, throughout many years. These games are consistently studied and copied by game designers because of their huge success; however, it is often not clear which characteristics made them successful. As a result, many new games inspired by these examples fail to achieve the same success. By separating the players who enjoy each of these games into unique groups, we provide insight into the reasons why these are so successful. Furthermore, we can understand and make inferences about how and why they appeal to different players, based on their player traits, gender, and attitude towards story.

Our work contributes to research in human-computer interaction (HCI) and games user research (GUR) by presenting novel insights about different patterns of play that emerge from empirical evidence provided by a cross-sectional correlational study with a large sample of players from diverse geographical regions. This will represent an invaluable reference model for the development of a definitive player trait model grounded by empirical evidence.

\section{RELATED WORK}

\subsection{Player Typologies}

BrainHex (Bateman, Lowenhaupt, \& Nacke, 2011; Nacke et al., 2014) is a top-down player typology, which is informed by and has elements of neurobiological player satisfaction research (Bateman \& Nacke, 2010), 
previous typology approaches, discussions of patterns of play, and the literature on game emotions to build seven archetypes denoting distinct experiences of play. The seven BrainHex archetypes are as follows:

Table 1. BrainHex's seven archetypes (Bateman et al., 2011; Nacke et al., 2014).

\begin{tabular}{|c|c|}
\hline Achiever & $\begin{array}{l}\text { Achievers are goal-oriented and motivated by completion. They like to collect and } \\
\text { complete everything they can find. They prefer to carry out series of tasks within their } \\
\text { reach, distinct from Conquerors, who prefer to overcome difficult obstacles. }\end{array}$ \\
\hline Conqueror & $\begin{array}{l}\text { Conquerors enjoy struggling against strong opponents until they achieve victory. They } \\
\text { channel their anger to achieve victory. }\end{array}$ \\
\hline Daredevil & $\begin{array}{l}\text { Daredevils are motivated by excitement, risk taking, and playing on the edge. They } \\
\text { enjoy rushing around at high speed while still being in control of the experience. }\end{array}$ \\
\hline Mastermind & $\begin{array}{l}\text { Masterminds enjoy solving puzzles, devising strategies, and making the most efficient } \\
\text { decisions. They feel rewarded by making well-thought decisions. }\end{array}$ \\
\hline Seeker & $\begin{array}{l}\text { Seekers are motivated to explore the game world and enjoy moments of wonder. This } \\
\text { motivation comes from the parts of the brain that process sensory information and } \\
\text { memory association. }\end{array}$ \\
\hline Socialiser & $\begin{array}{l}\text { Socialisers enjoy interacting with other people, talking to them, helping them, or just } \\
\text { hanging around. They are trusting and their behaviour connects to their social centre in } \\
\text { the brain. }\end{array}$ \\
\hline Survivor & $\begin{array}{l}\text { Survivors enjoy frightening experiences in the context of fictional activities. They can } \\
\text { be motivated by the intensity of the terror itself or by the relief felt afterwards. }\end{array}$ \\
\hline
\end{tabular}

Busch et al. (2016) conducted an initial validation of the BrainHex model and argued for an improvement of its psychometric properties, based on poor results of factor, stability, and internal consistency analyses. Nevertheless, they did not evaluate the underlying player traits that the BrainHex scale intended to uncover as suggested by Nacke and colleagues (2014), nor did Busch et al. (2016) test whether player type scores in the BrainHex survey can significantly predict player experience. Our work is motivated by these research shortcomings and seeks to answer both questions. 
Several previous player typologies are also available, presenting distinct models of player motivations. Hamari and Tuunanen (2014) reviewed these models and suggested that they could be synthesized in five key dimensions pertaining to motivations of play: Achievement, Exploration, Sociability, Domination, and Immersion. Additionally, they note that massive-multiplayer (MMOs) and online games are more frequently covered than other genres in several of these studies; therefore, compromising the generalizability of these models. Our work builds upon the BrainHex model, which was designed with a variety of games and genres in mind.

One of the oldest and most frequently cited player type models is Bartle's. Bartle (1996) studied what players desired from Multi-User Dungeons (MUDs) and identified four player types based on two axes that express the player's desire to interact with or act on the virtual world or other players: Achievers (acting on the world), Explorers (interacting with the world), Socialisers (interacting with other players), and Killers (acting on other players). Bartle (2005) later extended it by adding a third dimension: implicit/explicit (i.e., whether the player actions are automatic and unconscious or considered and planned). Thus, each of the four original types was split into two sub-types. The implicit sub-types are respectively Opportunists, Hackers, Friends, and Griefers. The explicit sub-types are respectively Planners, Scientists, Networkers, and Politicians.

Based on a factor analysis of questions inspired by the original Bartle's player types, Yee (2006) and Yee, Ducheneaut, and Nelson (2012) identified three main components of player motivation with ten subcomponents: achievement (advancement, mechanics, competition), social (socializing, relationship, teamwork), and immersion (discovery, roleplaying, customization, escapism). Although their analyses provide a solid base for understanding player motivation, they suffer from the same issue as Bartle's: both were strongly focused on one specific game genre (in this case, Massively Multiplayer Online Role-Playing Games - MMORPGs). 
More recently, Yee (2015) expanded on his previous work by conducting a factor analysis with a large number of participants and developed a Gamer Motivation Profile composed of 12 dimensions grouped in 6 clusters:

- Action: Destruction and Excitement;

- Social: Competition and Community;

- Mastery: Challenge and Strategy;

- Achievement: Competition and Power;

- Immersion: Fantasy and Story; and

- Creativity: Design and Discovery.

Although Yee's (2015) recent investigation intends to capture player motivations towards a large variety of games, and is empirically supported by factor analysis, a standard assessment tool is still not publicly and readily available. Our research addresses this player assessment gap by creating a methodology for assessing player traits.

Another widely known theory of what players enjoy about games is Lazzaro's (2004) “4 keys 2 fun”, which has four elements: Hard Fun (triumph over adversity), Easy Fun (curiosity), Serious Fun (relaxation and excitement), and People Fun (amusement).

Sherry, Lucas, Greenberg, and Lachlan (2006) surveyed the most common reasons from using video games and classified them in six dominant dimensions: arousal, challenge, competition, diversion, fantasy, and social interaction. These dimensions are described as gratifications obtained from playing games. The authors also devised and validated a 27 -items scale to measure players' motivations towards each one of these gratifications. Furthermore, Greenberg, Sherry, Lachlan, Lucas, and Holmstrom (2010) employed this scale in a large-scale survey to investigate player preferences. They found differences in players' scores based on gender and age. Moreover, they note that stronger preferences for different types of gratifications, 
as well as gender and age, might be significant factors in predicting typical game play hours and genre preference.

\subsection{Player Preferences Based on Personality Factors}

Jeng and Teng (2008) investigated the relation between the five-factor model of personality (Goldberg, 1993) and motivations to play games. They found that some personality factors support specific play styles; however, they did not study how these relationships apply to different games. Peever, Johnson, and Gardner (2012) investigated the preferences for game genres based on the player's five-factor personality traits. Fang, Chan, and Nair (2009) proposed a motivational model of videogame engagement, which suggests that game play enjoyment is the result of a fit between the characteristics of the player and elements of the game. Furthermore, Fang and Zhao (2010) employed this framework to investigate the relationship between game enjoyment and two personality traits: sensation seeking and self-forgetfulness. They found significant correlations of these personality traits with several game genres. Our study also aims to investigate preferences for different games. However, we consider that even games with similar genres can spark different player motivations. Thus, we opted to analyse player motivations related to each game individually and then group them based on the data, without a prior genre categorization.

Ryan, Rigby, and Przybylski (2006) and Przybylski, Rigby, and Ryan (2010) built a motivational model of video game engagement based on self-determination theory (Deci \& Ryan, 1985; Ryan \& Deci, 2000). They propose that competence, autonomy, relatedness, presence, and intuitive controls are good predictors of player enjoyment and engagement. Their player motivation model can explain why a game is successful. However, it does not account for individual differences between games and player preferences. If two games are equally able to satisfy players' psychological needs, it is not clear what attributes make players prefer one game to the other.

GameFlow (Sweetser, Johnson, \& Wyeth, 2012; Sweetser \& Wyeth, 2005) is a tool to evaluate games in each of the elements necessary to afford the experience of flow (Csikszentmihalyi, 1990): concentration, challenge, player skills, control, clear goals, feedback, immersion, and social interaction. GameFlow allows 
the comparison of games of similar genres to predict which one will be more enjoyable. However, it cannot explain why players prefer one game to another when both are equally providing the experience of flow. Our work aims to address some of these limitations by comparing player preferences for games that are equally successful.

Several authors have investigated how players' perceived values and identification with game characters, avatars (a graphical representation of the user), and objects increase player motivation and enjoyment in digital games. Birk, Atkins, Bowey, and Mandryk (2016) showed that avatar customization stimulates player identification, leading to increased experienced autonomy, immersion, invested effort, enjoyment, and positive affect. Livingston, Gutwin, Mandryk, and Birk (2014) interviewed twenty World of Warcraft (Blizzard Entertainment, 2004) players with the goal of investigating what kind of value their game characters provided. Tondello, Wehbe, Toups, Nacke, and Crenshaw (2015) and Toups, Crenshaw, Wehbe, Tondello, and Nacke (2016) built upon their work to examine why players value and collect a diversity of game objects, including, but not limited to, characters. While these frameworks can help explain part of a player's preferences for different games, they are limited to one of the many aspects that define a game, namely their characters or objects. Our work aims to build a more generic framework to identify general patterns of play.

\subsection{Players' Motivations towards Specific Games}

Ducheneaut, Yee, Nickell, and Moore (2006) collected and analysed several metrics related to players' activities in World of Warcraft. Their work provided many insights on how players interact with the game and what they enjoy about it. However, their analysis is limited to one game. Jansz and Tanis (2007) conducted an online survey of 751 players of online first-person shooter (FPS) games to gather information about this group. Their results suggest FPS players are highly motivated by challenges and competition. Additionally, more than $80 \%$ of respondents were members of a clan, and social motivation was a predictor of time spent in the game. Frostling-Henningsson (2009) interviewed Counter-Strike (Valve Corporation, 2000) and World of Warcraft players and found social reasons represented their main motivation to play, 
allowing for cooperation and communication. While presenting useful insights, her analysis was limited to two games and players' motivations were not separated clearly. Williams, Consalvo, Caplan, and Yee (2009) surveyed EverQuest II (Sony Online Entertainment, 2004) players and found that men were more motivated by achievement whereas women were slightly more motivated by social interactions. Our work aims to be more general than these studies, because we are analysing games of different genres and seeking to identify which motivations lead players to prefer one game to another.

\section{STUDY I: THE PLAYER TRAITS MODEL}

In the first study, our goal was to devise a player traits model that is grounded on empirical evidence, is applicable to diverse types and genres of games, and is based out of survey items that are readily available to researchers. Additionally, we also intended to estimate how players score in these traits on average and how these scores are influenced by demographic factors, such as gender and age. Therefore, we conducted a cross-sectional correlational study based on the available data. A correlational study is a type of empirical research that aims to answer questions about the association between observed variables (Landers \& Bauer, 2015). It differs from experimental or quasi-experimental studies, in which some variables are manipulated by the researchers to test a causal question, because there is no variable manipulation in a correlational study. Furthermore, a cross-sectional study design is employed in correlational research when the survey contains all the variables of interest.

The overarching goals of the study corresponded to the following research questions:

RQ1: What are the individual traits that influence players' preferences towards different games?

RQ2: What are the average scores of players on these traits?

RQ3: How do demographic factors influence players' scores on these traits?

To answer these questions, we first evaluated how well the scale suggested by Nacke and colleagues (2014) can measure the underlying player motivations in diverse games using a reliability analysis. However, the 
initial results showed that the scale was not able to consistently measure seven distinct playing styles. Consequently, we analysed the BrainHex data using Structural Equation Modeling (SEM) to explore the relationship between the items in the scale and devise a model representing the player traits that emerged from an empirical analysis of the data. The emergent model explains player preferences in terms of three distinct traits, instead of the original seven. Finally, we studied the relationship between these three player traits and participants' demographic information (gender, age, and attitude towards story) to better understand the defining characteristic of each trait.

\subsection{Methods}

\subsubsection{Survey instrument}

For this study, we revisited the survey data collected by Nacke et al. (2014) through an online survey conducted between 2009 and 2010. The survey consisted of three parts. The first part asked participants questions about their demographic information and questions related to their gaming attitude and preference. These questions included the importance of game narrative to players and three games that they enjoyed playing the most. The second and third parts of the survey correspond to Nacke et al.'s (2014) BrainHex scale. Thus, the second part consisted of 21 statements about different gameplay styles that the participants preferred; each statement corresponded to one BrainHex archetype. Participants subjectively rated their agreement to each of the statements on a 5-point Likert scale. Finally, the third part consisted of seven statements, which participants had to rank from first to seventh in order of preference. As before, each statement corresponded to one of the BrainHex types.

\subsubsection{Participants}

The survey was completed by 50,423 participants (44,684 men, 5,737 women, 2 did not disclose), with a mean age of 24.5 years $(S D=7.4)$. The geographical distribution of participants was as follows: North America (50\%); Western Europe (28\%); Eastern Europe and Russia (8\%); South America (4\%); Australasia (4\%); South Asia (2\%); and other (4\%). 
Most respondents identified themselves as mid-core players (59\%), followed by hard-core (24\%) and casual players (15\%). However, this is a subjective classification based solely on self-reported answers, as the dataset did not provide additional information regarding the participants' actual hours of game playing per day. Thus, despite informative to describe the variety of the sample, we chose not to use this variable in our analyses. Furthermore, while most respondents preferred multiplayer gaming (over the Internet, 20\%; in the same room, $17 \%$; MMORPGs, $13 \%$; team play, $9 \%$ ), $41 \%$ of the population engaged primarily in singleplayer games. Most respondents agreed that stories can help them enjoy games (54\%) or that stories are an important aspect of their game enjoyment (38\%).

\subsection{Results}

In this section, we present the results of the analyses we conducted to answer our research questions. They are organized as follows:

Response to RQ1: analysis of the internal consistency of the original scale and identification of the player traits emergent from the data;

Response to RQ2: description of the player traits emerged from the data; and

Response to RQ3: influence of demographics on the player traits' scores.

\subsubsection{Internal consistency of the original scale}

We analysed the internal consistency of the original BrainHex scale by separately calculating Cronbach's $\alpha$ for the items associated with each archetype. First, we calculated the scores by using the complete BrainHex scale (i.e., its two sections). In the complete scale, each BrainHex archetype is represented by four items: in the first section, the first three items per archetype are scored in a Likert scale; and in the second section, the last (fourth) item per subscale is rated in comparison with the statements for the other archetypes. After computing the results, we noted that all subscales lacked consistency (see Table 2). Therefore, we decided to also compute the internal consistency scores for each subscale using just the first three items from the survey because they were scored in a Likert scale, different from the fourth item. We 
found that the 3-items subscales perform better (see Table 2). Therefore, we decided to disregard the fourth item on each scale and focus only on the first three items per subscale for all subsequent analyses. Despite this change, the results showed that all archetypes have low internal consistency, even when considering only the first three items per subscale. Therefore, we concluded that the original BrainHex scale is not a good representation of the underlying player preferences.

\section{Table 2. Internal consistency of the original BrainHex scale.}

\begin{tabular}{lcc}
\hline BrainHex archetype & $\boldsymbol{\alpha}(\mathbf{4}$ items $)$ & $\boldsymbol{\alpha}$ (3 items) \\
\hline Achiever & .289 & .286 \\
Conqueror & .088 & .237 \\
Daredevil & .219 & .220 \\
Mastermind & .063 & .276 \\
Seeker & .206 & .330 \\
Socialiser & -.031 & .462 \\
Survivor & .257 & .523 \\
\hline
\end{tabular}

\subsubsection{Identification of the player traits emergent from the data}

Considering Nacke et al.'s (2014) suggestion to look at BrainHex as an interim model to further study player traits and that our initial analysis revealed that the BrainHex scale had low internal consistency, we decided to conduct an exploratory analysis using SEM to investigate the underlying player traits that would emerge from the data. The results provide the answer to $\mathbf{R Q 1}$.

To accomplish this, we began by introducing the seven BrainHex archetypes to the model as latent variables and the 21 items from the survey as observed variables. In SEM, latent variables are the underlying constructs we are modeling (in our study, there are the player traits) and observed variables are the indicators used to measure the latent constructs (in our study, these are the items from the BrainHex scale). We used a reflective model because the survey items are measurable consequences of the underlying player traits. Hence, the three items associated with each archetype were modeled as reflections of the respective 
latent variable. We conducted the analysis using partial least squares path modeling (also known as PLSSEM) with the software SmartPLS version 3.2.6 (SmartPLS, Bönningstedt, Germany, 2016). In this study, we were interested in the measurement model because our goal was to verify if the items of the BrainHex survey can be used as indicators of the latent variables, which represent the distinct player motivations.

After solving the equation and analysing the results provided by SmartPLS, we noted problems of consistency and discriminant validity with the variables. First, there were issues with the cross loadings of the observed variables (survey items) in the latent variables (archetypes). There were two types of problems: some variables did not show a high loading to any factor, whereas other variables showed high loadings for several (more than half) of the archetypes. Thus, we identified the variables that did not show a loading in their correspondent latent variable with a coefficient at least .20 points above all the other latent variables. These items failed SmartPLS's model consistency and discriminant validity; therefore, we removed them before repeating the analysis, as recommended by Hair Jr, Hult, Ringle, \& Sarstedt (2016).

After removing the observed variables that were not contributing to discriminate between the latent variables, we still observed issues of discriminant validity, measured by the heterotrait-monotrait ratio of correlations (HTMT) (Henseler, Ringle, \& Sarstedt, 2015). HTMT is an estimate of the correlations between different factors; thus, the authors suggest using a threshold value of less than .90 to identify factors with good discriminant validity. SmartPLS calculates the HTMT between all latent variables taken two by two. Therefore, following Henseler and colleagues' (2015) guidelines for treating discriminant validity problems, we decided to merge the pairs of constructs that showed a HTMT value greater than .90 (i.e., that lacked discriminant validity) into more general constructs.

After completing these two steps, we repeated the analysis until all the SmartPLS model validity indicators were satisfied. Figure 1 summarizes the procedure we employed to answer RQ1. 


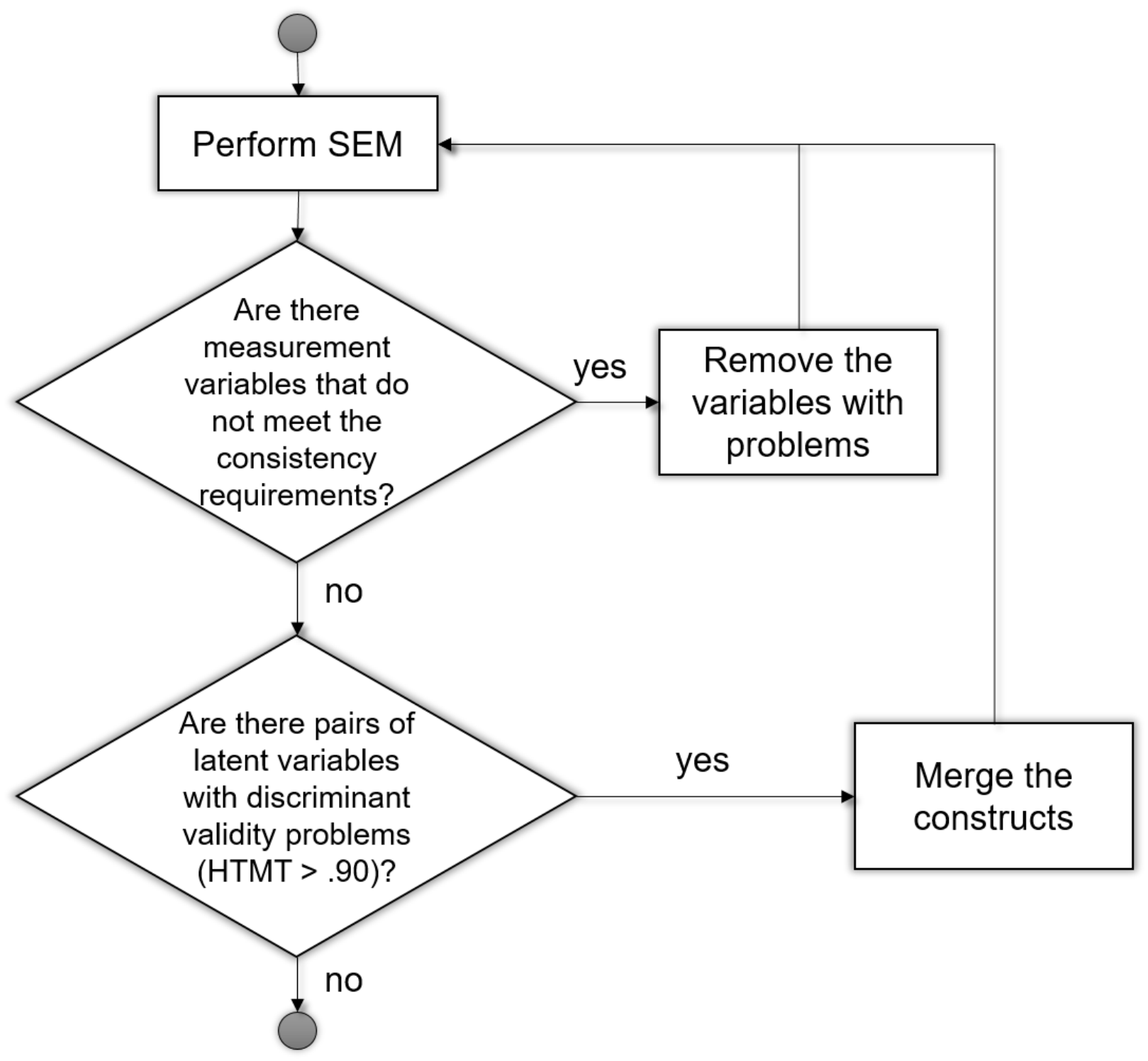

Final model achieved

Figure 1. Procedure employed to solve the problems of consistency and discriminant validity.

On completion of the analytic procedure, we retained 14 of the 21 items from the original BrainHex survey, which satisfied the model validity and inclusion criteria. Furthermore, after merging the constructs that lacked discriminant validity, we had merged the seven original archetypes into three constructs, as suggested by the exploratory analysis: 
1. The first construct included items from the Conqueror and Daredevil archetypes. It included survey items related with action, difficult challenges, and excitement; thus, we identified it as an indicator of players' action orientation.

2. The second construct included items from the Socialiser and Seeker archetypes. It included survey items related with social activities and exploration; hence, following the hint of Nacke et al.'s (2014) interpretation of socialization and exploration as the esthetics of wonder and esthetics of interpersonal relationships, respectively, we identified it as an indicator of players' esthetic orientation.

3. The third construct included items from the Achiever, Mastermind, and Survivor archetypes. It includes survey items related with completing collections, solving puzzles, and devising strategies to solve a problem; therefore, we identified it as an indicator of players' goal orientation.

Figure 2 presents the final path model with the loadings of each observed variable in their respective latent variable's measurement. Table 3 presents the final cross loadings of the observed variables for all the constructs. Finally, Table 4 presents the HTMT coefficients for the final model.
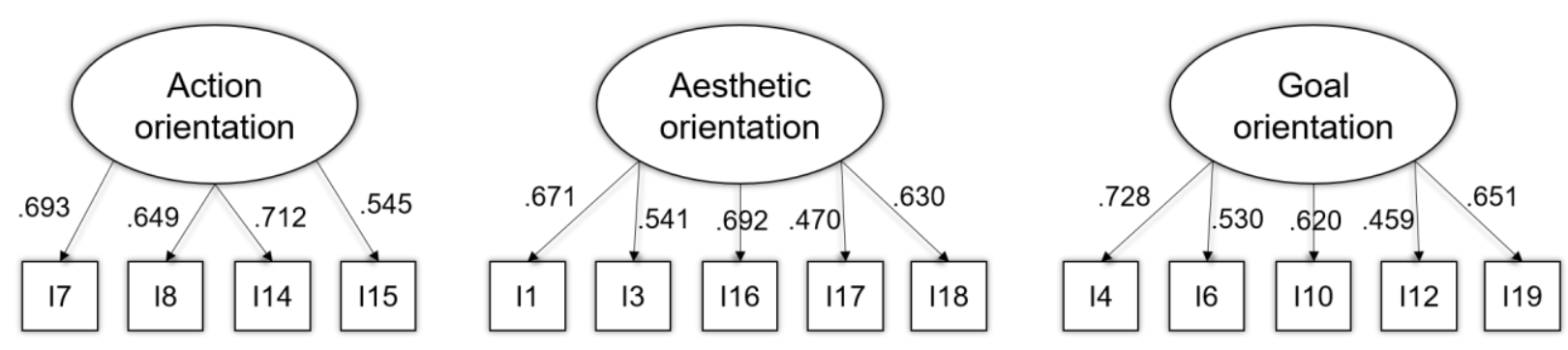

Figure 2. Final path model and outer loadings. 
Table 3. Cross loadings for the final model.

Latent Variables

\begin{tabular}{|c|c|c|c|}
\hline BrainHex Items & $\begin{array}{l}\text { 1- Action } \\
\text { Orientation }\end{array}$ & $\begin{array}{l}\text { 2- Aesthetic } \\
\text { Orientation }\end{array}$ & $\begin{array}{c}\text { 3- Goal } \\
\text { Orientation }\end{array}$ \\
\hline I14- "Taking on a strong opponent in a versus match" & .712 & .297 & .129 \\
\hline I7- "Feeling excited" & .693 & .299 & .097 \\
\hline I8- "Being in control at high speed" & 649 & .336 & -.011 \\
\hline $\begin{array}{l}\text { I15- "Completing a punishing challenge after failing } \\
\text { many times" }\end{array}$ & .545 & .305 & .149 \\
\hline I16- "Talking to non-player characters" & .406 & .692 & .119 \\
\hline I1- "Exploring to see what you can find" & .417 & 671 & .063 \\
\hline I18- "Co-operating with strangers" & .204 & .630 & .267 \\
\hline I3- "Wondering what's behind a locked door" & .167 & .541 & .264 \\
\hline I17- "Talking to other players" & .165 & .470 & .184 \\
\hline I4- "Running away from a dangerous foe" & .107 & .196 & .728 \\
\hline I19- "Picking up every single collectible in an area" & .135 & .187 & .651 \\
\hline I10- "Cracking a challenging puzzle" & .046 & .199 & .620 \\
\hline I6- "Feeling relief when you escape to a safe area" & .085 & .103 & .530 \\
\hline I12- "Working out what to do on your own" & -.035 & .041 & .459 \\
\hline Merged archetypes & $\begin{array}{l}\text { Conqueror } \\
\text { Daredevil }\end{array}$ & $\begin{array}{c}\text { Seeker } \\
\text { Socialiser }\end{array}$ & $\begin{array}{c}\text { Achiever } \\
\text { Mastermind } \\
\text { Survivor }\end{array}$ \\
\hline Composite reliability & .746 & .740 & .738 \\
\hline
\end{tabular}

Note. The principal loadings for each item are marked in bold. 
Table 4. Heterotrait-Monotrait Ratio (HTMT) coefficients for the final model.

\begin{tabular}{lccc}
\hline Latent Variable & $\mathbf{1}$ & $\mathbf{2}$ & $\mathbf{3}$ \\
\hline 1- Action Orientation & - & & \\
2- Aesthetic Orientation & .802 & - & \\
3- Goal Orientation & .299 & .484 & - \\
\hline
\end{tabular}

The internal consistency for the final model (with three player traits) is adequate because the composite reliability scores (which are a more precise estimation for PLS-SEM models than Cronbach's $\alpha$ ) are all above .70 (see Table 3 and cf. with Table 2). Moreover, discriminant validity was also achieved because all HTMT values are below .90. Finally, the standardized root mean square residual (SRMR) SmartPLS reported for our model was .109 , whereas the recommended threshold is that a value less than .10 represents a good model fit (Ringle et al., 2015). Therefore, we can conclude that the final model represents an adequate fit.

\subsubsection{Description of the player traits emerged from the data}

To describe players' characteristics regarding the three traits identified from the SEM and answer RQ2, we calculated the scores for each participant on each trait as the weighted average of the participant's selfreported answers to the BrainHex items that are part of each trait in the final model, considering the weights from the final path model. The weighted average is a more precise computation than a simple average because it takes into considerations the weights calculated by the SEM. The survey items consisted of 5point Likert scales; therefore, the scores for each trait could vary from 1.0 to 5.0. These analyses were all carried out using the software SPSS v. 23 (IBM, Armonk, New York, US, 2015).

Goal orientation was the stronger trait in the sample on average $(M=4.13, S D=0.64)$, followed by esthetic orientation $(M=3.95, S D=0.58)$, and, finally, by action orientation $(M=3.55, S D=0.69)$. However, the difference between them is not large; there is only $11.6 \%$ difference between the strongest and weakest trait. 


\subsubsection{Influence of demographics on the player traits' scores}

To identify which demographic factors influence players' scores in the three traits and answer RQ3, we analysed the influence of participants' genders, ages, and attitudes towards game story on their player trait scores.

Table 5 presents the results of the independent samples t-test of the player trait scores between participants' genders. It indicates that women tend to score higher in action orientation (small-to-medium effect), whereas men tend to score higher in goal orientation (also a small-to-medium effect). Women also scored significantly higher than men in esthetic orientation, but the effect is small.

Table 5. Independent samples t-test of player trait scores between genders $(N=\mathbf{5 0 , 4 2 1})$.

\begin{tabular}{|c|c|c|c|c|c|c|c|c|}
\hline Player traits & Gender & mean & SD & $t$ & $d f$ & $p$ & $\begin{array}{c}\text { mean } \\
\text { diff. }\end{array}$ & $d$ \\
\hline $\begin{array}{l}\text { 1- Action } \\
\text { orientation }\end{array}$ & $\begin{array}{l}\text { Female } \\
\text { Male }\end{array}$ & $\begin{array}{l}3.788 \\
3.523\end{array}$ & $\begin{array}{l}0.652 \\
0.690\end{array}$ & 27.354 & 50419 & $<.001$ & 0.265 & .395 \\
\hline $\begin{array}{l}\text { 2- Aesthetic } \\
\text { orientation }\end{array}$ & $\begin{array}{l}\text { Female } \\
\text { Male }\end{array}$ & $\begin{array}{l}4.009 \\
3.948\end{array}$ & $\begin{array}{l}0.583 \\
0.575\end{array}$ & 7.616 & 50419 & $<.001$ & 0.008 & .105 \\
\hline $\begin{array}{l}\text { 3- Goal } \\
\text { orientation }\end{array}$ & $\begin{array}{l}\text { Female } \\
\text { Male }\end{array}$ & $\begin{array}{l}3.919 \\
4.156\end{array}$ & $\begin{array}{l}0.687 \\
0.627\end{array}$ & -26.635 & 50419 & $<.001$ & -0.237 & -.360 \\
\hline
\end{tabular}

The bivariate correlation coefficients (Pearson's $r$ ) between player trait scores and participants' ages were all significant $(p<.01)$, but all effects are minor: $r=.026$ for action orientation; $r=.105$ for esthetic orientation; and $r=-.120$ for goal orientation. It seems that the orientation towards goal achievement slightly decreases with age. On the other hand, action and esthetic orientations seem to slightly increase with age, but the effect sizes are almost negligible.

Finally, Table 6 presents the results of the one-way analysis of variance (ANOVA) of the player trait scores between participants' distinct attitudes towards story in videogames. All effects are significant and they seem to be directionally ordered according to participants' enjoyment of stories (i.e., the more a participant 
reports to enjoy videogame stories, the higher their scores in all player traits). Nonetheless, the effect sizes $\left(\eta^{2}\right)$ for action and esthetic orientations are moderate, whereas they are small for goal orientation.

Table 6. One-way analysis of variance of player trait scores between distinct attitudes towards videogame stories $(N=\mathbf{5 0 , 4 2 1})$.

\begin{tabular}{|c|c|c|c|c|c|c|c|}
\hline \multirow{2}{*}{\multicolumn{2}{|c|}{ Attitude Towards Videogame Stories }} & \multirow{2}{*}{\multicolumn{2}{|c|}{$\begin{array}{c}\text { 1- Action } \\
\text { Orientation }\end{array}$}} & \multirow{2}{*}{\multicolumn{2}{|c|}{$\begin{array}{l}\text { 2- Aesthetic } \\
\text { Orientation }\end{array}$}} & \multirow{2}{*}{\multicolumn{2}{|c|}{$\begin{array}{c}\text { 3- Goal } \\
\text { Orientation }\end{array}$}} \\
\hline & & & & & & & \\
\hline & & $M$ & $S D$ & $M$ & $S D$ & $M$ & $S D$ \\
\hline \multicolumn{2}{|c|}{ "I don't play videogames" } & 2.899 & 1.02 & 3.213 & 1.07 & 3.233 & 1.16 \\
\hline \multicolumn{2}{|c|}{ "I prefer videogames without stories" } & 3.066 & 0.81 & 3.526 & 0.71 & 3.847 & 0.76 \\
\hline \multicolumn{2}{|c|}{ "Stories are not important to me in videogames" } & 3.174 & 0.76 & 3.645 & 0.65 & 4.090 & 0.67 \\
\hline \multicolumn{2}{|c|}{ "Stories can help me enjoy a videogame" } & 3.520 & 0.66 & 3.924 & 0.55 & 4.140 & 0.61 \\
\hline \multicolumn{2}{|c|}{$\begin{array}{l}\text { "Stories are very important to my enjoyment of } \\
\text { videogames" }\end{array}$} & 3.696 & 0.66 & 4.080 & 0.54 & 4.141 & 0.65 \\
\hline \multirow[t]{4}{*}{ ANOVA Results: } & $F$ & \multicolumn{2}{|c|}{645.985} & \multicolumn{2}{|c|}{721.169} & \multicolumn{2}{|c|}{154.276} \\
\hline & $d f$ & \multicolumn{2}{|c|}{4,50416} & \multicolumn{2}{|c|}{4,50416} & \multicolumn{2}{|c|}{4,50416} \\
\hline & $p$ & \multicolumn{2}{|c|}{$<.001$} & \multicolumn{2}{|c|}{$<.001$} & \multicolumn{2}{|c|}{$<.001$} \\
\hline & $\eta^{2}$ & \multicolumn{2}{|c|}{.049} & \multicolumn{2}{|c|}{.054} & \multicolumn{2}{|c|}{.012} \\
\hline
\end{tabular}

\subsection{Study I Discussion}

In this study, we followed the request for further research by Nacke et al. (2014) and conducted an exploratory analysis on the data collected for their BrainHex survey using statistical methods with the goal of identifying the player traits that explain player preferences for the different game mechanics and playing styles. When a new psychometric scale is developed, it is part of the normal procedure to create an initial, hypothetical scale based on the theory, which must then be validated by statistical methods. As a regular part of this procedure, it is also common to identify survey items that failed to contribute to the scale as intended, which are then removed from the scale. Similarly, the analysis often identifies a need to merge or split the theorized latent constructs, as the data shows empirical evidence related to these constructs. 
Nonetheless, despite having been previously published, the BrainHex scale had never been through this validation process until now; hence, this was one of the main goals of our study.

Nacke and colleagues (2014) had suggested that a two-traits or a four-traits model could potentially emerge from the data. However, since their suggestion was based on a qualitative evaluation of the relationships between the BrainHex archetypes and the MBTI types, it was hypothetical. Empirical evidence was a requirement to validate the theory, but until now, we still lacked an empirical verification of this hypothesis. With the introduction of the present work, we completed this verification.

To provide the empirical evidence needed, we have decided to take a different approach and use Structure Equation Modeling, which is an established method to analyse models of latent and observed variables. By doing so, we decided to distance our analysis from the MBTI types, considering that the latest research on personality has generally favoured the trait models instead of typologies such as the MBTI.

Our analysis revealed a model with three latent player traits: action orientation, esthetic orientation, and goal orientation. Thus, the results supported neither the two-traits nor the four-traits models hypothesized by Nacke and colleagues (2014). Nonetheless, the three traits revealed by our analysis seem to correspond respectively to the visceral, esthetic, and goal oriented traits of their theorized four-traits model. Thus, our analysis supports their initial findings and complements them with a more precise trait model grounded on solid statistical methods.

Furthermore, we demonstrate that there are significant differences in the overall player trait scores by gender. Women appear to score higher in action orientation; on the other hand, men appear to score higher in goal orientation. Williams et al. (2009) had previously found that men scored higher in achievement motivations, which included both action (combat) and goals. Thus, our analysis is more detailed because it separates action and goal orientation, whereas Williams et al. examined both together. Our results support their prior findings regarding goal oriented gameplay, but not regarding action oriented gameplay. Finally, 
women also scored slightly higher in esthetic orientation, but the effect size was small; therefore, it seems that esthetic orientation is the most similar player trait between men and women.

The effects of age on the player trait scores were also significant, which seemed to be mostly because of our large sample size considering the effects were small. Thus, unless future studies reveal stronger effects, we can conclude these player traits vary little with age.

Finally, the attitude towards stories in videogames was associated with the player's trait scores. However, our results cannot explain if there is a causal relation between the attitude towards story and player traits (nor which is the direction of this causation, if it even exists), or if they merely occur simultaneously because of an external, unknown cause. In any case, the results show that higher action and esthetic orientations usually occur together with the higher perception of the importance of stories for videogames, whereas goal orientation does not seem to be very related with the importance of stories.

Upon completion of our analytical procedure, the revised BrainHex scale retained 14 out of the 21 originally

suggested items - the remaining items were removed because they did not contribute to the internal neither to the discriminant validity of the scale. The revised 14 -items survey can be considered a validated scale to score an individual's scores in each one of the three traits of our model.

In the next study, we will compare these player trait scores with participants' reported preferences for different games, which will enable us to test how well these traits can explain different playing preferences.

\section{STUDY II: UNDERSTANDING PARTICIPANTS' ENJOYMENT OF DIFFERENT GAMES}

In the second part of this study, we build on the previous study by analysing the games listed by participants as examples of the games they enjoy, to understand how different player traits lead to practical differences in the games they enjoy. To achieve this, we compared participants' scores in the three player traits uncovered in the first study (action, esthetic, and goal orientation) with the groups of games they said they 
enjoy, to understand how they are related. This allowed us to test the ability of the new player trait model to predict players' preferences towards different games.

\subsection{Methods}

Similar to the previous study, these findings originate from the dataset described above. To examine which games exemplified enjoyable game mechanics for each player trait, we needed to analyse participants' answers to the question "Name three games that exemplify what you enjoy about games". Since participants answered through a free-entry text field, we had to organize and standardize their responses before the analysis (e.g., resolve abbreviations, handle spelling errors, and unify naming variations). All analyses in this study were conducted using the software SPSS 23 (IBM, 2015).

\subsubsection{Free-Text Data Cleaning}

We deemed the naïve approach of using raw data from the free-entry text fields as insufficient, as the responses oftentimes contained abbreviations, such as "WoW" (full: World of Warcraft), spelling errors, such as "Baynetta" (correct: Bayonetta), and naming variations, such as "The Legend of Zelda: Ocarina of Time", "Ocarina of Time", and "Zelda: Ocarina of Time". This created a unique problem for grouping the same games, or games of the same franchise, together.

To deal with these three challenges and accurately group games with similar names, we created a matching algorithm, which required neither a dictionary of known game names nor an exact match between game names. We controlled for misspelled game names by using a letter matching algorithm then manually verifying all the game names post-match to ensure that we included as much of the sample data as possible so our data was not biased by excluded cases.

The algorithm compared the free-text entries pairwise by calculating a letter matching difference score. The score was calculated by counting the number of letters mismatched between two responses and dividing the result by the sum of the lengths of both responses. For example, the difference between "Bayonetta" and "Baynetta" is one letter out of a total of $9+8=17$ letters; this results in a matching difference of 1 / 
$17=0.059$. The first letter was given double the weight of other letters to prioritize its matching because the first letter of a game name was usually correct, even if the name was misspelled otherwise.

We classified game names with a matching difference of 0.15 or lower as being the same. We iteratively reached this number by manually inspecting 1,000 randomly picked game names. The result indicated that a matching difference of 0.15 was the highest threshold for which no false-positive groupings occurred.

Last, we grouped game names with a matching difference of 0.15 or lower together to find game names that were distant, but related. Upon completion, all game groups were automatically labelled based on a generalized label that was derived from the shared text in the grouped game names. For example, "Final Fantasy VII" and "Final Fantasy 6" were labelled as "Final Fantasy". Similarly, "Zelda: Ocarina of Time" and "The Legend of Zelda" were labelled as "Zelda" as it is the only text shared between both entries. A manual verification of the top 26 games (see Table 7) revealed that there were no false-positive matches in the data set.

We chose to use a custom string matching approach over existing algorithms, such as Levenstein distance and Jaro-Winkler distance, since it produced zero false-positive matches in our specific dataset. Previous research comparing string matching algorithms by Cohen et al. (2003) has shown the precision of popular algorithms can vary depending on the characteristics of the dataset. It is possible that the algorithm described here may be less effective for other datasets.

\subsubsection{Game Selection and Grouping}

In the relabelled data set, 3,289 games were mentioned two times or more by the participants. For the purposes of this study, we focused on a meaningful subset of these games based on the frequency of their mentioning. Therefore, we included only game franchises that participants mentioned at least 1,000 times. This selection criterion narrowed our scope from 3,289 to 26 games and game franchises (see Table 7), which accounted for $42 \%$ of game mentions in the survey. Even after this reduction, we retained $77 \%$ of the total participants in the dataset. This indicated that $77 \%$ of participants responded with at least one game 
from one of the top 26 franchises. This selection was done to reduce the sample of games we had to analyse to a meaningful subset. The remaining $23 \%$ of the participants were split between 3,263 games, leaving these games to be mentioned between one and five times in total within the entire sample. If we had not filtered our dataset, it would have been more diluted with less meaningful comparisons.

\section{Table 7. Game counts for the most commonly cited games.}

\begin{tabular}{lcc}
\hline \multicolumn{1}{c}{ Game } & Frequency & \% of total \\
\hline Baldur's Gate (BioWare, 1998) & 1,426 & $2.2 \%$ \\
Battlefield (Digital Illusions, 2002) & 1,076 & $1.7 \%$ \\
Bioshock (2K Boston \& 2K Australia, 2007) & 1,537 & $2.4 \%$ \\
Call of Duty (Infinity Ward, 2003) & 3,988 & $6.2 \%$ \\
Civilization (MPS Labs, 1991) & 1,967 & $3.1 \%$ \\
Counter-Strike (Valve Corporation, 2000) & 1,819 & $2.8 \%$ \\
Deus Ex (Ion Storm, 2000) & 1,224 & $1.9 \%$ \\
Diablo (Blizzard North, 1996) & 1,971 & $3.1 \%$ \\
Elder Scrolls (Bethesda Softworks, 1994) & 2,620 & $4.1 \%$ \\
Fallout (Interplay Entertainment, 1997) & 3,765 & $5.9 \%$ \\
Final Fantasy (Square, 1987) & 4,875 & $7.6 \%$ \\
Grand Theft Auto (DMA Design, 1997) & 1,671 & $2.6 \%$ \\
Half-Life (Valve Corporation, 1998) & 3,480 & $5.5 \%$ \\
Halo (Bungie, 2001) & 2,751 & $4.3 \%$ \\
Left 4 Dead (Turtle Rock Studios, 2008) & 2,037 & $3.2 \%$ \\
Mass Effect (BioWare, 2007) & 2,834 & $4.4 \%$ \\
Metal Gear Solid (Konami, 1987) & 1,726 & $2.7 \%$ \\
Pokémon (Game Freak, 1996) & 1,064 & $1.7 \%$ \\
Portal (Valve Corporation, 2007) & 1,131 & $1.8 \%$ \\
Starcraft (Blizzard Entertainment, 1998) & $7.0 \%$ \\
Super Mario (Nintendo R\&D4, 1985) & $2.5 \%$ \\
\hline & & \\
\hline
\end{tabular}




\begin{tabular}{lcc}
\hline Super Smash Bros. (HAL Laboratory, 1999) & 1,169 & $1.8 \%$ \\
Team Fortress (Valve Corporation, 1999) & 3,782 & $5.9 \%$ \\
Warcraft (Blizzard Entertainment, 1994) & 1,330 & $2.1 \%$ \\
World of Warcraft (Blizzard Entertainment, 2004) & 5,978 & $9.4 \%$ \\
Zelda (Nintendo, 1986) & 2,589 & $4.1 \%$ \\
\hline Total & $\mathbf{6 3 , 8 3 6}$ & $\mathbf{1 0 0 . 0} \%$ \\
\hline
\end{tabular}

To measure the impact of our data cleaning effort, we performed a similar grouping as described above but with the raw dataset instead. For this, a total of 5,389 games were mentioned two times or more. The selection criterion of 1,000 participants resulted in 17 games and game franchises, which accounted for $21 \%$ of game mentions in the survey. Without cleaning the data, we would have retained only $49 \%$ of participants (instead of 77\%). This comparison shows that data cleaning indeed improved data quality as it retained twice as many mentions of games (from $21 \%$ to $42 \%$ ) while keeping over 75 per cent of the population in the sample. It also removed skew from the data because some titles are more prone to abbreviations, spelling errors, and naming variations than others. Call of Duty, for example, would have lost two-thirds of its count and Half-Life (now $7^{\text {th }}$ ) would not have appeared on the list of most mentioned franchises at all. Overall, our data cleaning approach required no manual effort besides setting the desired matching difference and verifying the final results; we recommend it to other researchers who set out to process similar data.

After relabelling, we used a Principal Component Analysis (PCA) with Oblimin rotation to group the top 26 franchises based on their co-occurrence in participants' responses. This was done because participants had the option of citing up to three games in their free-form entry. Thus, the groups of games often cited together were a more accurate representation of participants' player type than individual games (e.g., some players may like both FPS and RPG games). Hence, games that were grouped together by the PCA in each principal component were frequently reported together by participants as exemplars of what they enjoyed in games, indicating that games within a group appealed to similar types of players. 
We used Parallel analysis and Velicer's Minimum Average Partial test (O’Connor, 2000) to determine the optimal number of game groups (principal components). The tests returned 11 significant groups. After examining the structure matrix, however, we found that some of the games in the groupings were on opposite ends of the same axis. This suggested that players who listed one game were unlikely to list the other game. For example, participants who listed Civilization were unlikely to list Counter-Strike and viceversa. We found that out of the 1,819 times Counter-Strike and 1,967 times Civilization were listed, they co-occurred only 33 times (less than 1\%). To address this in the final groupings, we separated games that were negatively correlated with others within the same factor into their own groups. This increased the number of game groups from 11 to 14 (see Table 8). We used this grouped dataset for all further analyses.

Table 8. Game groups based on the co-occurrence of the most commonly cited games (alphabetically sorted).

\begin{tabular}{lrr}
\hline Game Group & Frequency & \% of total \\
\hline 1. Baldur's Gate, Deus Ex & 2,650 & $4.2 \%$ \\
2. Battlefield & 1,076 & $1.7 \%$ \\
3. Bioshock, Mass Effect & 4,371 & $6.8 \%$ \\
4. Call of Duty, Halo & 6,739 & $10.6 \%$ \\
5. Civilization & 1,967 & $3.1 \%$ \\
6. Counter-Strike & 1,819 & $2.8 \%$ \\
7. Diablo, Starcraft, Warcraft & 7,754 & $12.1 \%$ \\
8. Elder Scrolls, Fallout & 6,385 & $10.0 \%$ \\
9. Final Fantasy, Metal Gear Solid & 6,601 & $10.3 \%$ \\
10. Grand Theft Auto & 1,671 & $2.6 \%$ \\
11. Half-Life, Portal & 4,611 & $7.2 \%$ \\
12. Left 4 Dead, Team Fortress & 5,819 & $9.1 \%$ \\
13. Pokémon, Super Mario, Super Smash Bros., Zelda & 6,395 & $10.0 \%$ \\
\end{tabular}




\section{Total}

63,836

$100.0 \%$

\subsubsection{Participants}

After filtering and grouping our dataset by game groups, 38,803 unique respondents remained (35,117 males, 3,686 females), with a mean age of 24.1 years $(S D=6.8)$. This represents $77 \%$ of the original 50,423 participants. The descriptive statistics for player trait scores in the filtered dataset remained similar to the values from the complete dataset used in the first study (see section 3.2.3). Goal orientation remained the strongest trait $(M=4.17, S D=0.61)$, followed by esthetics orientation $(M=3.96, S D=0.57)$ and action orientation $(M=3.55, S D=0.68)$.

\subsubsection{Hypotheses}

We hypothesized there would be a significant difference in player trait scores for participants who mentioned different games and game franchises because the player traits are supposed to capture distinct preferences:

H1: The participant's player trait scores will have an effect on their game preferences.

Additionally, Williams et al. (2009) and Greenberg et al. (2010) found differences in player motivation by gender. However, their investigations focused on the association of gender with specific game genres. Differently, our approach aims to investigate the correlation of gender with the game groups uncovered by our analysis, without any prior genre categorization; thus, we contend that this association warrants further investigation. Therefore, we hypothesized gender would have an effect on participants' preferences towards the game groups.

H2: The participant's gender will have an effect on their game preferences.

Moreover, the PCA seemed to divide games with more or less focus on a story or narrative into different group and our dataset included information about participants' attitudes towards game story: whether they 
prefer games without story, enjoy games with story without considering the story essential, or consider stories an important part of their enjoyment of games. Thus, we hypothesized the participant's attitude towards game story would have an effect on their preferences towards the game groups:

H3: The participant's attitude towards game story will have an effect on their game preferences.

Moving forward with these hypotheses, we performed another statistical analysis to gain insight from the dataset.

\subsection{Results}

To test hypothesis H1, we used the one-way analysis of variance (ANOVA) of the player trait scores between the different game groups using $\eta^{2}$ as the effect size and calculating a $90 \%$ confidence interval for $\eta^{2}$ using Smithson's (2002) method.

We used Pearson's $\chi^{2}$ to test the hypotheses $\mathbf{H 2}$ and $\mathbf{H 3}$ because they involved only categorical data. Pearson's $\chi^{2}$ is robust against imbalances in group sizes provided the table of expected frequencies does not contain values lower than five (Field, 2009, p. 691). Our data satisfied all the assumptions. Moreover, we calculated Cramer's $V$ as the effect size for $\mathbf{H 2}$ and $\mathbf{H 3}$, and used Smithson's (2002) method to calculate a 95\% confidence interval. Next, we used Volker's (2006) method to transform it into Cohen's effect size $w$, which we compared to Cohen's (1988) general standards. The probabilities reported here were calculated using the equation:

$$
P_{i j}=O F_{i j} / E F_{i j}
$$

where $P_{i j}=$ probability, $O F_{i j}=$ observed frequency, $E F_{i j}=$ expected frequency, and $i j=$ each pair of categories.

Furthermore, we compared the standardized residual of each cell with the critical values of $z$ to evaluate the significance of each probability ( $p<.05$ if $|z|>1.96 ; p<.01$ if $|z|>2.58 ; p<.001$ if $|z|>3.29$ ). We used the absolute values of $z$ to find the two-tailed probability values. 
For gender, we included the normalized probabilities of female respondents enjoying each game group in relation to male respondents, as well as the corresponding significance at the .05 level. We tested with posthoc $z$-tests between columns while adjusting $p$-values with a Bonferroni method.

The survey collected participants' attitudes towards game story through the question "My attitude to videogame stories is", with the following possible answers: "I don't play videogames", "I prefer videogames without stories", "Stories are not important to me in videogames", "Stories are very important to my enjoyment of videogames", and "Stories can help me enjoy a videogame". The answer "I don't play videogames" appeared in only 84 responses $(0.1 \%)$ and did not help us understand game preferences; thus, we removed it from the analysis. The answer "I prefer videogames without stories" appeared in only 545 responses $(0.9 \%)$; thus, we combined it with the answer "Stories are not important to me in videogames".

\subsubsection{Player Traits}

Hypothesis $\mathbf{H 1}$ was supported by the ANOVA tests, which showed that the three player traits influence participants' choice of games (see Table 9). The effect sizes $\left(\eta^{2}=.033, .034, .030\right.$, respectively for the three player traits) suggest effects between small and moderate in all cases.

Table 9. One-way analysis of variance of player trait scores between distinct game groups $(N=$ 63,836).

\begin{tabular}{|c|c|c|c|c|c|c|}
\hline \multirow[t]{2}{*}{ Game Groups } & \multicolumn{2}{|c|}{$\begin{array}{c}\text { 1- Action } \\
\text { Orientation }\end{array}$} & \multicolumn{2}{|c|}{$\begin{array}{l}\text { 2- Aesthetic } \\
\text { Orientation }\end{array}$} & \multicolumn{2}{|c|}{$\begin{array}{c}\text { 3- Goal } \\
\text { Orientation }\end{array}$} \\
\hline & $M$ & $S D$ & $M$ & $S D$ & $M$ & $S D$ \\
\hline 1. Baldur's Gate, Deus Ex & 3.347 & 0.728 & 3.801 & 0.602 & 4.309 & 0.566 \\
\hline 2. Battlefield & 3.681 & 0.670 & 4.028 & 0.561 & 4.199 & 0.582 \\
\hline 3. Bioshock, Mass Effect & 3.452 & 0.668 & 3.906 & 0.570 & 4.162 & 0.606 \\
\hline 4. Call of Duty, Halo & 3.492 & 0.644 & 4.054 & 0.500 & 4.032 & 0.645 \\
\hline 5. Civilization & 3.721 & 0.652 & 4.038 & 0.544 & 4.247 & 0.582 \\
\hline 6. Counter-Strike & 3.656 & 0.647 & 4.064 & 0.533 & 4.107 & 0.622 \\
\hline
\end{tabular}




\begin{tabular}{|c|c|c|c|c|c|c|c|}
\hline \multirow{2}{*}{\multicolumn{2}{|c|}{ Game Groups }} & \multicolumn{2}{|c|}{$\begin{array}{c}\text { 1- Action } \\
\text { Orientation }\end{array}$} & \multicolumn{2}{|c|}{$\begin{array}{l}\text { 2- Aesthetic } \\
\text { Orientation }\end{array}$} & \multicolumn{2}{|c|}{$\begin{array}{c}\text { 3- Goal } \\
\text { Orientation }\end{array}$} \\
\hline & & $M$ & $S D$ & $M$ & $S D$ & $M$ & $S D$ \\
\hline \multicolumn{2}{|c|}{ 7. Diablo, Starcraft, Warcraft } & 3.618 & 0.666 & 3.902 & 0.581 & 3.959 & 0.647 \\
\hline \multicolumn{2}{|c|}{ 8. Elder Scrolls, Fallout } & 3.554 & 0.644 & 4.044 & 0.528 & 4.052 & 0.643 \\
\hline \multicolumn{2}{|c|}{ 9. Final Fantasy, Metal Gear Solid } & 3.576 & 0.661 & 3.896 & 0.564 & 4.287 & 0.585 \\
\hline \multicolumn{2}{|c|}{ 10. Grand Theft Auto } & 3.401 & 0.656 & 3.953 & 0.519 & 3.996 & 0.646 \\
\hline \multicolumn{2}{|c|}{ 11. Half-Life, Portal } & 3.659 & 0.650 & 4.107 & 0.504 & 4.020 & 0.644 \\
\hline \multicolumn{2}{|c|}{ 12. Left 4 Dead, Team Fortress } & 3.455 & 0.694 & 3.826 & 0.599 & 4.127 & 0.626 \\
\hline \multicolumn{2}{|c|}{ 13. Pokémon, Super Mario, Super Smash } & 3.303 & 0.724 & 3.739 & 0.635 & 4.275 & 0.601 \\
\hline \multicolumn{2}{|c|}{ 14. World of Warcraft } & 3.516 & 0.698 & 3.872 & 0.600 & 4.223 & 0.595 \\
\hline \multirow[t]{5}{*}{ ANOVA Results: } & $F$ & \multicolumn{2}{|c|}{169.265} & \multicolumn{2}{|c|}{174.451} & \multicolumn{2}{|c|}{152.463} \\
\hline & $d f$ & \multicolumn{2}{|c|}{13,63822} & \multicolumn{2}{|c|}{13,63822} & \multicolumn{2}{|c|}{13,63822} \\
\hline & $p$ & \multicolumn{2}{|c|}{$<.001$} & \multicolumn{2}{|c|}{$<.001$} & \multicolumn{2}{|c|}{$<.001$} \\
\hline & $\eta^{2}$ & \multicolumn{2}{|c|}{.033} & \multicolumn{2}{|c|}{.034} & \multicolumn{2}{|c|}{.030} \\
\hline & $90 \%$ CI for $\eta^{2}$ & \multicolumn{2}{|c|}{$.031, .036$} & \multicolumn{2}{|c|}{$.032, .037$} & \multicolumn{2}{|c|}{$.028, .033$} \\
\hline
\end{tabular}

\subsubsection{Gender}

Hypothesis $\mathbf{H} 2$ was supported by the $\chi^{2}$ test: $\chi^{2}(13)=1,272.57, p<.001, V=.141(95 \% \mathrm{CI}=.134, .149)$, $w=.141(95 \% \mathrm{CI}=.134, .149)$. However, the effect size $(w=.141)$ suggests a small effect. Table 10 presents the standardized probabilities of occurrence of each game group and gender compared to the expected frequency if the variables were independent along with the significance levels. Additionally, Table 10 displays the probability ratio of a female participant playing each game group in comparison with a male participant. 
Table 10. Standardized probabilities of occurrence of each pair of game group and gender in comparison with the expected frequency if the variables were independent.

\begin{tabular}{|c|c|c|c|}
\hline Game Group & Female & Male & Female/Male \\
\hline 1. Baldur's Gate, Deus Ex & $0.64^{* * *}$ & 1.03 & $0.62 *$ \\
\hline 2. Battlefield & $0.24^{* * *}$ & $1.07^{*}$ & $0.23^{*}$ \\
\hline 3. Bioshock, Mass Effect & 1.07 & 0.99 & 1.08 \\
\hline 4. Call of Duty, Halo & $0.47^{* * *}$ & $1.05^{* * *}$ & $0.45^{*}$ \\
\hline 5. Civilization & $0.80^{*}$ & 1.02 & $0.79^{*}$ \\
\hline 6. Counter-Strike & $0.43^{* * *}$ & $1.05^{*}$ & $0.41^{*}$ \\
\hline 7. Diablo, Starcraft, Warcraft & $0.57^{* * *}$ & $1.04^{* * *}$ & $0.55^{*}$ \\
\hline 8. Elder Scrolls, Fallout & 0.99 & 1.00 & 0.99 \\
\hline 9. Final Fantasy, Metal Gear Solid & $1.41^{* * *}$ & $0.96^{* *}$ & $1.46^{*}$ \\
\hline 10. Grand Theft Auto & $0.64^{* * *}$ & 1.03 & $0.62 *$ \\
\hline 11. Half-Life, Portal & $0.76^{* * *}$ & 1.02 & $0.74^{*}$ \\
\hline 12. Left 4 Dead, Team Fortress & $0.88^{* *}$ & 1.01 & $0.87^{*}$ \\
\hline 13. Pokémon, Super Mario, Super Smash Bros., Zelda & $1.75^{* * *}$ & $0.93^{* * *}$ & $1.88^{*}$ \\
\hline 14. World of Warcraft & $1.78^{* * *}$ & $0.93^{* * *}$ & $1.92 *$ \\
\hline
\end{tabular}

Note. In the first two columns, each cell's value represents how many times that combination is more probable (if value $>1.0$ ) or less probable (if value $<1.0$ ) to occur in our sample than it would occur if the variables were independent. The last column represents how many times a female player is more probable (if value $>1.0$ ) or less probable (if value < 1.0) to enjoy games of that group than a male player.

${ }^{*} p<.05 .{ }^{* *} p<.01 .{ }^{* * *} p<.001$.

\subsubsection{Attitude towards Story}

Hypothesis $\mathbf{H 3}$ was supported by the $\chi^{2}$ test: $\chi^{2}(26)=4,535.92, p<.001, V=.189(95 \% \mathrm{CI}=.183, .194)$, $w=.267(95 \% \mathrm{CI}=.259, .275)$. The effect size $(w=.267)$ suggests a medium effect. Table 11 presents the standardized probabilities of occurrence of each game group and attitude towards story compared to the expected frequency if the variables were independent and the significance levels. 
Table 11. Standardized probabilities of occurrence of each pair of game group and attitude towards story in comparison with the expected frequency if the variables were independent.

\begin{tabular}{|c|c|c|c|}
\hline \multirow[t]{2}{*}{ Game Group } & \multicolumn{3}{|c|}{ Attitude Towards Story } \\
\hline & $\begin{array}{c}\text { Not } \\
\text { Important }\end{array}$ & Helpful & Important \\
\hline 1. Baldur's Gate, Deus Ex & $0.19^{* * *}$ & $0.81^{* * *}$ & $1.40^{* * *}$ \\
\hline 2. Battlefield & $1.64^{* * * *}$ & $1.17^{* * *}$ & $0.65^{* * *}$ \\
\hline 3. Bioshock, Mass Effect & $0.17^{* * *}$ & $0.75^{\text {*** }}$ & $1.49^{* * *}$ \\
\hline 4. Call of Duty, Halo & $1.37^{* * *}$ & $1.03 *$ & $0.88^{* * *}$ \\
\hline 5. Civilization & $1.30^{* * *}$ & $1.10^{* *}$ & $0.81^{* * *}$ \\
\hline 6. Counter-Strike & $3.08^{* * *}$ & $1.09^{* *}$ & $0.50^{* * *}$ \\
\hline 7. Diablo, Starcraft, Warcraft & $1.94^{* * *}$ & $1.07^{* * *}$ & $0.73^{* * *}$ \\
\hline 8. Elder Scrolls, Fallout & $0.40^{* * *}$ & $0.89^{* * *}$ & $1.26^{* * *}$ \\
\hline 9. Final Fantasy, Metal Gear Solid & $0.31^{* * *}$ & $0.81^{\text {*** }}$ & $1.39^{* * *}$ \\
\hline 10. Grand Theft Auto & 0.98 & 1.05 & 0.94 \\
\hline 11. Half-Life, Portal & $0.52^{* * *}$ & 0.98 & $1.11^{* * *}$ \\
\hline 12. Left 4 Dead, Team Fortress & 1.07 & $1.21^{* * *}$ & $0.70^{* * *}$ \\
\hline 13. Pokémon, Super Mario, Super Smash Bros., Zelda & 0.99 & $1.11^{* * *}$ & $0.85^{* * *}$ \\
\hline 14. World of Warcraft & $1.21^{* * *}$ & $1.05^{* *}$ & $0.89^{* * *}$ \\
\hline
\end{tabular}

$\overline{\text { Note. } \text { Each cell's value represents how many times that combination is more probable (if value > 1.0) or less probable }}$ (if value < 1.0) to occur in our sample than it would occur if the variables were independent.

${ }^{*} p<.05 .{ }^{* *} p<.01 .^{* * *} p<.001$.

\subsection{Study II Discussion}

The results support all presented hypotheses and demonstrate significant effects of players' trait scores, genders, and their attitude towards story in relation to game preference. Therefore, we looked at them 
together (Tables 9, 10, and 11) to understand which player characteristics might predict their preference for specific game groups. We summarized the results in Table 12, which contains the following columns:

Strongest player traits: The player traits which scores are considerably above the average for the players that listed games from the group as examples of what they enjoy.

Gender preference: The gender that most frequently lists games from the group as examples of what they enjoy.

Attitude towards story: The importance of story for the enjoyment of games from the group; inferred from attitudes toward story of participants' who listed games from the group as examples of what they enjoy.

Notes: The main characteristics of the games in the group, as well as additional insights that we inferred from further analysis of each game group's data.

Table 12. Motivations by Game Group.

\begin{tabular}{|c|c|c|c|c|}
\hline Game Group & $\begin{array}{c}\text { Strongest } \\
\text { Player } \\
\text { Traits }\end{array}$ & $\begin{array}{c}\text { Gender } \\
\text { Preference }\end{array}$ & $\begin{array}{c}\text { Attitude } \\
\text { Towards } \\
\text { Story }\end{array}$ & Notes \\
\hline $\begin{array}{l}\text { 1. Baldur's Gate, } \\
\text { Deus Ex }\end{array}$ & Aesthetic & Males & $\begin{array}{c}\text { very } \\
\text { important }\end{array}$ & $\begin{array}{l}\text { This game group includes two role-playing game } \\
\text { series with strong narratives. Players seem to enjoy } \\
\text { the freedom to explore the game world and interact } \\
\text { with the story. }\end{array}$ \\
\hline 2. Battlefield & none & Males & $\begin{array}{c}\text { not } \\
\text { important }\end{array}$ & $\begin{array}{l}\text { This game group is represented by a series of first- } \\
\text { person shooters with strong team-based gameplay. It } \\
\text { seems that men are more likely to enjoy this game } \\
\text { than women; whereas all the player trait scores were } \\
\text { below average for players in this group. }\end{array}$ \\
\hline $\begin{array}{l}\text { 3. Bioshock, } \\
\text { Mass Effect }\end{array}$ & $\begin{array}{l}\text { Action, } \\
\text { Aesthetic }\end{array}$ & none & $\begin{array}{c}\text { very } \\
\text { important }\end{array}$ & $\begin{array}{l}\text { This game group includes two series of first-person } \\
\text { or third-person shooters with action role-playing } \\
\text { elements and immersive storylines. Players seem to } \\
\text { like the freedom to explore the game world while } \\
\text { feeling the thrill of the story. }\end{array}$ \\
\hline
\end{tabular}




\begin{tabular}{|c|c|c|c|c|}
\hline $\begin{array}{l}\text { 4. Call of Duty, } \\
\text { Halo }\end{array}$ & Goals & Males & $\begin{array}{c}\text { not } \\
\text { important }\end{array}$ & $\begin{array}{l}\text { This group includes two first-person shooter (FPS) } \\
\text { game series, which also offer multiplayer modes. It } \\
\text { seems to engage players with goal achievement. }\end{array}$ \\
\hline 5. Civilization & none & Males & $\begin{array}{c}\text { not } \\
\text { important }\end{array}$ & $\begin{array}{l}\text { This game group represents the game genre of turn- } \\
\text { based } 4 X \text { strategy games. }{ }^{a} \text { None of the investigated } \\
\text { variables could convincingly explain player } \\
\text { preferences for this game. }\end{array}$ \\
\hline 6. Counter-Strike & Goals & Males & $\begin{array}{c}\text { not } \\
\text { important }\end{array}$ & $\begin{array}{l}\text { This game group is represented by a series of } \\
\text { competitive, multiplayer, first person shooters. It } \\
\text { seems to engage players with the challenge of } \\
\text { completing goals in a competitive environment. }\end{array}$ \\
\hline $\begin{array}{l}\text { 7. Diablo, } \\
\text { Starcraft, } \\
\text { Warcraft }\end{array}$ & Goals & Males & not & $\begin{array}{l}\text { This group includes two real-time strategy (RTS) and } \\
\text { one action role-playing game series. They seem to } \\
\text { engage players with strategic challenges. } \\
\text { Additionally, the unifying aspect of these games - all } \\
\text { were published by Blizzard Entertainment - might } \\
\text { indicate some degree of publisher loyalty or } \\
\text { preference from gamers. }\end{array}$ \\
\hline $\begin{array}{l}\text { 8. Elder Scrolls, } \\
\text { Fallout }\end{array}$ & $\begin{array}{l}\text { Action, } \\
\text { Aesthetic }\end{array}$ & none & $\begin{array}{c}\text { very } \\
\text { important }\end{array}$ & $\begin{array}{l}\text { This game group contains two action, role-playing, } \\
\text { open world game series. }{ }^{\mathrm{b}} \text { Players seem to enjoy the } \\
\text { freedom to explore the game world, as well as the } \\
\text { excitement provided by the challenges. }\end{array}$ \\
\hline $\begin{array}{l}\text { 9. Final Fantasy, } \\
\text { Metal Gear Solid }\end{array}$ & $\begin{array}{l}\text { Action, } \\
\text { Aesthetic, } \\
\text { Goals }\end{array}$ & Females & $\begin{array}{c}\text { very } \\
\text { important }\end{array}$ & $\begin{array}{l}\text { This group includes two Japanese game series: a role- } \\
\text { playing game (RPG) and an action-adventure. It is } \\
\text { noteworthy that this is one of the game groups } \\
\text { strongly preferred by women, and that players } \\
\text { generally scored above average in all traits for this } \\
\text { group. Moreover, players seem to enjoy interacting } \\
\text { with the games' storylines. }\end{array}$ \\
\hline $\begin{array}{l}\text { 10. Grand Theft } \\
\text { Auto }\end{array}$ & Action & Males & indifferent & $\begin{array}{l}\text { This game group is represented by a series of open- } \\
\text { world action-adventure games. Players seem to be } \\
\text { drawn by the possibility of engaging in exciting and } \\
\text { fast-paced gameplay. }\end{array}$ \\
\hline $\begin{array}{l}\text { 11. Half-Life, } \\
\text { Portal }\end{array}$ & Aesthetic & Males & important & $\begin{array}{l}\text { This game group includes two game series, one first- } \\
\text { person shooter and one puzzle-platform, both }\end{array}$ \\
\hline
\end{tabular}


developed by Valve Corporation and set in the same

science-fiction universe. They seem to attract players

with the possibility of exploring their fictional

universes and their narratives. Additionally, the

unifying aspects of these games - the game publisher

and universe - might indicate some degree of

publisher loyalty or preference from gamers.

This game group includes two cooperative first-

12. Left 4 Dead,

Team Fortress

none Males helpful

person shooter series. None of the investigated

variables could convincingly explain player

preferences for these games.

This group includes four Japanese game series: an

action-adventure, a platformer, a fighting, and a role-

13. Pokémon,

Super Mario,

Super Smash

Bros., Zelda

Action,

playing series, all published by Nintendo. Therefore,

Bros, Zelda

Aesthetic, Females helpful

it might also reveal a degree of publisher or console

Goals

loyalty from gamers. Like group 9 , it is also

noteworthy that this is one of the game groups

strongly preferred by women, and that players

generally scored above average in all traits for this

group.

This game group represent the genre of massively

multiplayer online (MMO) role-playing games.

Despite this being a MMO game, the scores for

players in the social (aesthetic) trait were generally

14. World of

Warcraft

Goals Females

not

below average, which suggests that the social

important

motivation is not as strong as the motivation for goal achievement. It is also noteworthy that, although the game features a storyline, it is not its focus, and this fact shows by the fact that most players who listed this game do not care too much for the story in videogames.

\footnotetext{
Notes.

a $4 \mathrm{X}$ is a genre of strategy-based games in which the player controls an empire to "eXplore, eXpand, eXploit, and eXterminate".

${ }^{\mathrm{b}}$ The survey was conducted before the announcement of The Elder Scrolls Online; thus, we consider The Elder Scrolls as an Action-RPG game series instead of a MMO.
} 
The goal of this study was to test the ability of the new player trait model to predict players' preferences towards different games, together with information about the player's gender and attitude towards story. By supporting all three hypotheses, the results support the usefulness of this model as a predictor of player's enjoyment of different games. Nonetheless, despite finding significant effects overall, a detailed inspection of Table 12 shows that the influence of each factor on player's choices is not uniform between different games, meaning that for each game a different set of factors might be more important in determining players choices.

For example, the player traits seem to be able to describe distinct players preferences for some of the game groups, such as 4 (Call of Duty, Halo), 6 (Counter-Strike), and 7 (Diablo, Starcraft, Warcraft), which all showed a stronger preference for participants with higher goal-orientation. However, there were other game groups which were mentioned by participants who scored high in all traits in average, such as 9 (Final Fantasy, Metal Gear Solid) and 13 (Pokémon, Super Mario, Super Smash Bros., Zelda), as well as game groups which were mentioned by participants who scored lower in all traits in average, such as 2 (Battlefield) and 5 (Civilization).

Similarly, although gender seemed to be a determinant factor of player preference for most of the game groups, there were two game groups that showed no significant distinction in gender preferences: 3 (Bioshock, Mass Effect) and 8 (Elder Scrolls, Fallout). Attitude towards story was a significant factor for player preference for all game groups except group 10 (Grand Theft Auto).

These observations lead to two additional insights:

1. Multiple factors need to be considered when trying to predict player preferences for different games. For some games, the player's traits seem to be the strongest determinant of choice, whereas other games show a stronger differentiation in terms of gender preferences, and yet some other games are more or less appealing to players depending on their attitudes towards stories in games. 
2. While game genre might be a useful categorization, it might not be enough to determine the factors of player preference. For example, Table 12 shows that game groups 8 (Elder Scrolls, Fallout), 9 (Final Fantasy, Metal Gear Solid), and 14 (World of Warcraft), which could all be potentially described as groups of role-playing games, have remarkably distinct factors of participant preferences.

\section{GENERAL DISCUSSION}

By presenting the results of two studies on player preferences conducted over a large sample of more than 50,000 participants, we have demonstrated there are at least three reliable player traits, which partly explain what players enjoy in games: action orientation, esthetic orientation, and goal orientation. However, these traits showed only a small-to-moderate effect in the participants' choice of games. This resulted in some game groups in which participants scored generally low or generally high for all player traits. Therefore, we can conclude that, although these traits are useful for helping us explain player preferences, there are still additional factors or traits that remain unknown.

Our results illustrate that the player's attitude towards stories might be one of the additional factors. Games with strong narratives and stories appeared together in groups 1 (Baldur's Gate and Deus Ex), 3 (Bioshock and Mass Effect), and 9 (Final Fantasy and Metal Gear Solid). Although most participants in our sample consider story an important or enjoyable game element, data analysis could reveal that participants who consider story an important game element frequently cited strongly story-oriented games, whereas participants who consider story not important in games frequently cited games with a weaker story focus. This suggests that attitude towards story may be an additional factor to be included in a complete player trait model, which was not initially envisioned in the BrainHex model. Previous literature has investigated the effect of narrative comprehension and telling on the brain (Chow et al., 2014; Mar, 2011; Sanford \& Emmott, 2012), as well as the differences in narrative tendencies between individuals (Newman, 2005), further strengthening the argument for the inclusion of a story-oriented (or perhaps immersion-oriented) component in a player trait model. 
Additionally, the results show clear differences between genders regarding gaming preferences. Women were more likely than men to list games from groups 9 (Final Fantasy and Metal Gear Solid), 13 (Pokémon, Super Mario, Super Smash Bros., and Zelda), and 14 (World of Warcraft). Women were as likely as men to cite games from groups 3 (Bioshock and Mass Effect) and 8 (Elder Scrolls and Fallout). Finally, women were less likely than men to cite games in all other groups. Thus, we presented supporting evidence that gender is an additional factor which influences players' choices of games.

Finally, participants often cited some of the games from the same publisher together, as can be seen in groups 7 (Diablo, Starcraft, and Warcraft), 11 (Half-Life and Portal), and 13 (Pokémon, Super Mario, Super Smash Bros., and Zelda). This seems to suggest a degree of players' loyalty or preference to specific publishers or consoles. Nevertheless, it is not clear if this occurs because players are loyal to the publisher and thus more likely to play and enjoy their games, or if it is because publishers often employ similar or connected elements in their different games and thus it is appealing to the same players.

It is notable that the only MMO in our list, World of Warcraft (group 14), showed higher averages for goal orientation, instead of esthetic orientation. This does not imply that sociability is not an important feature, as previous studies have shown that social relations keep players engaged for a longer period (FrostlingHenningsson, 2009; Jansz \& Tanis, 2007). Nevertheless, it might suggest that players who are drawn to the game may be mainly motivated by achievement and challenge, with the social motivation being secondary and increasing with time to keep them engaged longer. It is possible that this is a reflection of the complex achievement system introduced into World of Warcraft with the second expansion pack, Wrath of the Lich King, in 2008 (Blizzard Entertainment, 2008). Or, perhaps, the developers became aware that their player base desired more goal oriented gameplay because of player feedback and hence, introduced the achievement system.

\subsection{Limitations}

We derived a player trait model using only the BrainHex survey's items as our data source. Nonetheless, the BrainHex model was devised with the clear intention of representing a broad range of player motivations 
and aimed to enable further analyses leading toward a definitive player trait model. Therefore, we consider that it was an adequate data source for our work. However, our analysis of potential player traits was limited to the data available. Due to this limited data availability, we decided to not consider some of the selfreported data that could not be verified with objective measures, such as participants' self-identification as casual, mid-core, or hard-core players. To make up for this, we have also reported the additional analyses that we conducted considering both the data available in the survey and the other existing player motivation models. These results have led us to suggest that at least two additional player traits might exist (see above), which were not directly uncovered by our SEM analysis of the BrainHex survey. Thus, future studies with a larger pool of survey items are required to validate our findings and investigate these and other potential player traits that might not have been revealed in the current work.

Additionally, data collection occurred from 2009 to 2010, which influences results from the second study. However, our method of grouping individual games into franchises or series helped to mitigate this limitation, as the game franchises included in the analysis continue to be relevant and popular at present. Some of the game series, such as Final Fantasy, have remained popular for over a decade. It could be argued that the franchises we analysed are timeless classics, as many of them continue to be enjoyed by players today, while their mechanics and narratives continue to inspire modern game design. Nevertheless, several different games, series, and genres have also become popular in the last few years, which were not part of the collected data set. In particular, casual games have become increasingly popular and relevant in the past years. The genre of MMORPGs has also has seen several significant additions in the last years, which have come to compete with World of Warcraft. A replication of this study with present-day data could potentially lead to new insights into these newer developments; hence, we suggest this variation as a future avenue for research.

Finally, we have decided to limit our analysis to the game franchises that appeared at least 1,000 times in our cleaned data set, leading to our final list of 26 game franchises. However, our data set contained over 3,000 games and franchises that appeared at least 2 times, which could potentially be analysed. It should 
be noted that even though we only analysed such a limited sample of games, the top 26 games captured $77 \%$ of participants. This suggests that the remaining $23 \%$ are diluted over 3,000 game franchises.

\subsection{Contribution Towards a Definitive Player Traits Model and Future Work}

In addition to evaluating the factors that influence players' preferences for different games discussed above, it is necessary to compare the new player trait model proposed in this work with the existing models. Since Hamari and Tuunanen (2014) have already conducted a review of these models and suggested an unified view, we used their work as a base for our comparison. Additionally, it is worthwhile to also consider Yee's (2015) gamer motivation profile, which is aimed at describing a broad range of motivations and games and is also based on empirical factor analyses. Table 13 summarizes the results of this comparison.

Table 13. Comparison of our player trait model with the dimensions suggested by Hamari and Tuunanen (2014) and by Yee (2015).

\begin{tabular}{lcc}
\hline Player Traits & Hamari and Tuunanen's Review & Yee's Gamer Motivation Profile \\
\hline 1- Action Orientation & Domination & Action \\
2- Aesthetic Orientation & Sociability, Exploration & Social, Creativity \\
3- Goal Orientation & Achievement & Mastery, Achievement \\
- & Immersion & Immersion \\
\hline
\end{tabular}

There are several similarities between our three-traits model and the existing models, which contributes to reinforcing the nomological validity of our results. However, in comparison with these prior works, we contribute a model that has been validated by solid statistical methods and includes a scale that can be used to measure an individual's scores in each one of the three traits. Hamari and Tuunanen's (2014) model was derived from a literature review of several existing works on player types, many of them lacking empirical validation, and does not suggest any way of measuring an individual's preferences. Yee's (2015) model is also validated by statistical methods and includes a survey to assess players' scores; however, neither the results of the statistical analyses nor the survey are publicly available. Therefore, our contribution is the 
first one to present a survey to score players according to their preferences in videogame playing that is widely available for researchers and designers and is supported by empirical evidence.

Furthermore, a critical analysis of Table 13 leads to two considerations:

1. It seems that immersion might be an additional trait that was not covered by the original BrainHex survey's items and, thus, not revealed by our analysis. If we consider that immersion includes the enjoyment of stories and narratives in videogames, this reinforces what our analysis of participants' attitudes towards stories suggested. Therefore, it is very likely that immersion orientation should be an additional player trait in a definitive model.

2. Our model has grouped sociability and exploration (creativity) in a single trait (esthetic orientation), whereas both compared models have separated these factors in two dimensions. From the available data, it is not possible to determine at this moment whether both socialization and exploration are just different manifestations of a broader esthetic orientation (thus, suggesting they should remain unified in a definitive model), or if they are different enough to warrant separate traits in a definitive model.

Consequently, based on the available information, there is evidence that future studies should expand our three-traits player model into one of two possibilities:

a) a four-traits model, including: action, esthetic, goal, and immersion orientation; or

b) a five-traits model, including: action, social, esthetic, goal, and immersion orientation (here, we are suggesting a potential separation of social orientation from the remaining esthetic orientations).

Further investigation is required to distinguish between these potential scenarios and propose a definite player trait model. Thus, continuing our work in this area we plan to use these insights to revise the player traits model, with the goal of validating the three traits that have emerged from our analysis - action, esthetic, and goal orientation. We will consider the inclusion of additional traits that did not appear in our study, but are suggested by supplementary analyses, such as immersion and socialization. Furthermore, we plan to extend our methodology to design a predictive model around the quantitative data, which will be 
able to predict what games a player will enjoy based on their gender and player traits. Moreover, because our study showed that the original BrainHex scale was not reliable and contributed with a revised 14-items scale, we plan to further revise the scale in future work or even develop a new, more reliable scale, based on the newly proposed player traits model. Repeating this study with a revised scale and a newer sample will also potentially lead us to new important findings about the emergence of casual games and shifts in gaming culture.

Additionally, collecting qualitative data to understand why players prefer specific games would complement our quantitative approach. Thus, in future studies, we plan to conduct in-depth interviews with participants in addition to collecting questionnaire data. This will allow us to qualify each player trait with a rich description of its characteristics, derived from a thematic analysis of the interviews.

\section{CONCLUSION}

In the present article, we analysed a large dataset of responses regarding participants' preferences for different games and playing styles and uncovered three player traits, which partly explain players' preferences: action orientation, esthetics orientation, and goal orientation. Furthermore, we showed the validity of this player traits model by using it to partly explain participants' game preferences. Finally, we demonstrated that gender and attitude towards story (i.e., immersion orientation) also play an important role in determining players' preferences, thus suggesting them as additional dimensions in a definitive player traits model.

Our work contributes to GUR and HCI research by providing solid evidence of the traits that influence players' preferences towards different games. This information can help designers and researchers create games that might better entertain both specific and general audiences, through a better understanding of what types of experiences players seek in games. Additionally, these results might be used to inform personalized games or gameful applications (i.e., games or applications tailored to the interests of specific players or users). In the context of serious games and gameful applications, the ability to understand player 
preferences and design personalized experiences is of paramount importance because prior research has shown that they can be more effective in helping the players or users achieve their goals (e.g., Busch et al., 2015; Orji et al., 2013; Orji, Nacke, \& DiMarco, 2017). This article contributes to the accomplishment of this goal.

\section{ACKNOWLEDGEMENTS}

The authors would like to thank Chris Bateman and International Hobo for kindly providing access to the original BrainHex survey data set. We would also like to thank Anson Ho for his help with data filtering, Melissa Stocco for her help in previous versions of this manuscript, and the reviewers for their valuable suggestions to improving this manuscript.

\section{FUNDING}

This work was supported by the Games Institute, University of Waterloo. Gustavo Tondello would like to thank the National Council for Scientific and Technological Development of Brazil (CNPq) for his funding. Rita Orji would like to thank the Canadian Government Banting NSERC for her funding. Rina R. Wehbe would like to thank NSERC and Cheriton School of Computer Science, University of Waterloo for their

funding and support. Lennart Nacke and his research team would like to thank NSERC (RGPIN-4186222012, Discovery, SWaGUR CREATE), SSHRC (895-2011-1014, IMMERSe), CFI (35819), and Mitacs (IT07255) for kindly funding this research.

\section{ORCID}

Gustavo Fortes Tondello: http://orcid.org/0000-0002-4174-7245

Rina R. Wehbe: http://orcid.org/0000-0003-3677-5185

Rita Orji: http://orcid.org/0000-0001-6152-8034

Lennart E. Nacke: http://orcid.org/0000-0003-4290-8829 


\section{REFERENCES}

Bakkes, S., Tan, C. T., \& Pisan, Y. (2012). Personalised gaming. In Proceedings of The $8^{\text {th }}$ Australasian Conference on Interactive Entertainment Playing the System - IE '12 (pp. 1-10). ACM. http://doi.org/10.1145/2336727.2336731

Bartle, R. (1996). Hearts, Clubs, Diamonds, Spades: Players who suit MUDs. Journal of MUD Research, $1(1)$.

Bartle, R. (2005). Virtual Worlds: Why People Play. Massively Multiplayer Game Development, 2(1), $3-18$.

Bateman, C., Lowenhaupt, R., \& Nacke, L. E. (2011). Player Typology in Theory and Practice. In Proceedings of the 2011 DiGRA International Conference: Think Design Play.

Bateman, C., \& Nacke, L. E. (2010). The Neurobiology of Play. In Proceedings of Futureplay 2010 (pp. 1-8). Vancouver, BC, Canada: ACM. http://doi.org/10.1145/1920778.1920780

Birk, M. V, Atkins, C., Bowey, J. T., \& Mandryk, R. L. (2016). Fostering Intrinsic Motivation through Avatar Identification in Digital Games. In Proceedings of the $34^{\text {th }}$ Annual ACM Conference on Human Factors in Computing Systems. http://doi.org/10.1145/2858036.2858062

Blizzard Entertainment. (2004). World of Warcraft. Irvine, California, USA: Blizzard Entertainment.

Blizzard Entertainment. (2008). World of Warcraft: Wrath of the Lich King. Irvine, California, USA: Blizzard Entertainment.

Busch, M., Mattheiss, E., Orji, R., Fröhlich, P., Lankes, M., \& Tscheligi, M. (2016). Player Type Models Towards Empirical Validation. In Proceedings of the 2016 CHI Conference Extended Abstracts on Human Factors in Computing Systems - CHI '16. ACM. http://doi.org/10.1145/2851581.2892399

Busch, M., Mattheiss, E., Orji, R., Marczewski, A., Hochleitner, W., Lankes, M., ... Tscheligi, M. (2015). Personalization in Serious and Persuasive Games and Gamified Interactions. In Proceedings of the 
2015 Annual Symposium on Computer-Human Interaction in Play - CHI PLAY'15 (pp. 811-816). ACM. http://doi.org/10.1145/2793107.2810260

Chow, H. M., Mar, R. A., Xu, Y., Liu, S., Wagage, S., \& Braun, A. R. (2014). Embodied Comprehension of Stories: Interactions Between Language Regions and Modality-specific Neural Systems. Journal of Cognitive Neuroscience, 26(2), 279-295. http://doi.org/10.1162/jocn_a_00487

Cohen, J. (1988). Statistical power analysis for the behavioral sciences ( $2^{\text {nd }}$ ed.). New Jersey: Erlbaum.

Cohen, W., Ravikumar, P., \& Fienberg, S. (2003, August). A comparison of string metrics for matching names and records. In KDD Workshop on Data Cleaning and Object Consolidation, vol. 3 (pp. 73$78)$.

Csikszentmihalyi, M. (1990). Flow: The Psychology of Optimal Experience. New York: Harper Perennial.

Deci, E. L., \& Ryan, R. M. (1985). Intrinsic Motivation and Self-Determination in Human Behavior. New York and London: Plenum.

Ducheneaut, N., Yee, N., Nickell, E., \& Moore, R. J. (2006). Building an MMO with mass appeal: a look at gameplay in World of Warcraft. Games and Culture, 1(4), 281-317. http://doi.org/10.1177/1555412006292613

Fang, X., Chan, S., \& Nair, C. (2009). An Online Survey System on Computer Game Enjoyment and Personality. In J. A. Jacko (Ed.), Human-Computer Interaction. Interacting in Various Application Domains. HCI 2009. Lecture Notes in Computer Science, vol 5613 (pp. 304-314). Springer, Berlin, Heidelberg. http://doi.org/10.1007/978-3-642-02583-9_34

Fang, X., \& Zhao, F. (2010). Personality and enjoyment of computer game play. Computers in Industry, 61(4), 342-349. http://doi.org/10.1016/j.compind.2009.12.005

Field, A. (2009). Discovering Statistics Using SPSS (3 ${ }^{\text {rd }}$ Ed.). London, UK: Sage Publications. 
Frostling-Henningsson, M. (2009). First-person shooter games as a way of connecting to people: "Brothers in blood." CyberPsychology \& Behavior, 12(5), 557-562. http://doi.org/doi:10.1089/cpb.2008.0345

Goldberg, L. R. (1993). The structure of phenotypic personality traits. American Psychologist, 48(1), 2634. http://doi.org/10.1037/0003-066X.48.1.26

Greenberg, B. S., Sherry, J., Lachlan, K., Lucas, K., \& Holmstrom, A. (2010). Orientations to Video Games Among Gender and Age Groups. Simulation \& Gaming, 41(2), 238-259. http://doi.org/10.1177/1046878108319930

Hair Jr, J. F., Hult, G. T. M., Ringle, C., \& Sarstedt, M. (2016). A primer on partial least squares structural equation modeling (PLS-SEM). Sage Publications.

Hamari, J., \& Tuunanen, J. (2014). Player types: A meta-synthesis. Transactions of the Digital Games Research, 1(2). Retrieved from http://todigra.org/index.php/todigra/article/view/13

Henseler, J., Ringle, C. M., \& Sarstedt, M. (2015). A new criterion for assessing discriminant validity in variance-based structural equation modeling. Journal of the Academy of Marketing Science, 43(1), 115-135. http://doi.org/10.1007/s11747-014-0403-8

Jansz, J., \& Tanis, M. (2007). Appeal of playing online first person shooter games. CyberPsychology \& Behavior, 10(1), 133-136. http://doi.org/10.1089/cpb.2006.9981

Jeng, S.-P., \& Teng, C.-I. (2008). Personality and motivations for playing online games. Social Behavior and Personality: An International Journal, 36(8), 1053-1060. http://doi.org/10.2224/sbp.2008.36.8.1053

Landers, R. N., \& Bauer, K. N. (2015). Quantitative methods and analyses for the study of players and their behavior. In P. Lankoski \& S. Björk (Eds.), Game Resarch Methods (pp. 151-173). Pittsburgh, PA: ETC Press.

Lazzaro, N. (2004). Why we play games: Four keys to more emotion without story. In Game Developers 
Conference. XEODesign. Retrieved from http://www.citeulike.org/group/596/article/436449

Livingston, I. J., Gutwin, C., Mandryk, R. L., \& Birk, M. (2014). How players value their characters in World of Warcraft. In Proceedings of the $17^{\text {th }}$ ACM conference on Computer Supported Cooperative Work \& Social Computing (pp. 1333-1343). http://doi.org/10.1145/2531602.2531661

Mar, R. A. (2011). The Neural Bases of Social Cognition and Story Comprehension. Annual Review of Psychology, 62, 103-134. http://doi.org/10.1146/annurev-psych-120709-145406

Nacke, L. E., Bateman, C., \& Mandryk, R. L. (2014). BrainHex: A Neurobiological Gamer Typology Survey. Entertainment Computing, 5(1), 55-62. http://doi.org/10.1016/j.entcom.2013.06.002

Newman, K. (2005). The Case for the Narrative Brain. In Proceedings of the Second Australasian Conference on Interactive Entertainment (pp. 145-149). ACM.

O'Connor, B. P. (2000). SPSS and SAS programs for determining the number of components using parallel analysis and Velicer's MAP test. Behavior Research Methods, Instruments, \& Computers, 32(3), 396402. http://doi.org/10.3758/BF03200807

Orji, R., Mandryk, R. L., Vassileva, J., \& Gerling, K. M. (2013). Tailoring persuasive health games to gamer type. In Proceedings of the SIGCHI Conference on Human Factors in Computing Systems CHI '13 (pp. 2467-2476). ACM. http://doi.org/10.1145/2470654.2481341

Orji, R., Nacke, L. E., \& DiMarco, C. (2017). Towards Personality-driven Persuasive Health Games and Gamified Systems. In Proceedings of the SIGCHI Conference on Human Factors in Computing Systems - CHI '17 (pp. 1015-1027). ACM. https://doi.org/10.1145/3025453.3025577

Peever, N., Johnson, D., \& Gardner, J. (2012). Personality \& Video Game Genre Preferences. In Proceedings of The $8^{\text {th }}$ Australasian Conference on Interactive Entertainment: Playing the System (p. 20). ACM. http://doi.org/10.1145/2336727.2336747

Przybylski, A. K., Rigby, C. S., \& Ryan, R. M. (2010). A motivational model of video game engagement. 
Review of General Psychology, 14(2), 154-166. http://doi.org/10.1037/a0019440

Ryan, R. M., \& Deci, E. L. (2000). Self-determination theory and the facilitation of intrinsic motivation, social development, and well-being. The American Psychologist, 55(1), 68-78. http://doi.org/10.1037/0003-066X.55.1.68

Ryan, R. M., Rigby, C. S., \& Przybylski, A. (2006). The motivational pull of video games: A selfdetermination theory approach. Motivation and Emotion, 30(4), 347-363. http://doi.org/10.1007/s11031-006-9051-8

Sanford, A. J., \& Emmott, C. (2012). Mind, Brain and Narrative. Cambridge, UK: Cambridge University Press.

Sherry, J. L., Lucas, K., Greenberg, B. S., \& Lachlan, K. (2006). Video Game Uses and Gratifications as Predictors of Use and Game Preference. In P. Vorderer \& J. Bryant (Eds.), Playing Video Games: Motives, Responses, and Consequences (pp. 248-262). New York and London: Routledge.

Smithson, M. (2002). Confidence Intervals (Vol. 140). Thousand Oaks, CA: SAGE.

Sony Online Entertainment. (2004). EverQuest II. San Diego, California, USA: Sony Online Entertainment.

Sweetser, P., Johnson, D. M., \& Wyeth, P. (2012). Revisiting the GameFlow model with detailed heuristics. Journal: Creative Technologies, 2012(3).

Sweetser, P., \& Wyeth, P. (2005). GameFlow: a model for evaluating player enjoyment in games. Computers in Entertainment (CIE), 3(3). http://doi.org/10.1145/1077246.1077253

Tondello, G. F., Wehbe, R. R., Toups, Z. O., Nacke, L. E., \& Crenshaw, N. K. (2015). Understanding Player Attitudes Towards Digital Game Objects. In Proceedings of the 2015 Annual Symposium on Computer-Human Interaction in Play - CHI PLAY '15 (pp. 709-714). London, United Kingdom: ACM. http://doi.org/10.1145/2793107.2810292 
Toups, Z. O., Crenshaw, N. K., Wehbe, R. R., Tondello, G. F., \& Nacke, L. E. (2016). "The Collecting Itself Feels Good": Towards Collection Interfaces for Digital Game Objects. In Proceedings of the 2016 Annual Symposium on Computer-Human Interaction in Play - CHI PLAY'16 (pp. 276-290). Austin, TX, United States: ACM. http://doi.org/10.1145/2967934.2968088

Valve Corporation. (2000). Counter-Strike. Bellevue, Washington, USA: Valve Corporation.

Volker, M. A. (2006). Reporting effect size estimates in school psychology research. Psychology in the Schools, 43(6), 653-672. http://doi.org/10.1002/pits.20176

Williams, D., Consalvo, M., Caplan, S., \& Yee, N. (2009). Looking for gender: Gender roles and behaviors among online gamers. Journal of Communication, 59(4), 700-725. http://doi.org/10.1111/j.14602466.2009.01453.x

Yee, N. (2006). Motivations for Play in Online Games. CyberPsychology \& Behavior, 9(6), 772-775. http://doi.org/10.1089/cpb.2006.9.772

Yee, N. (2015, December). Gamer Motivation Model Overview and Descriptions. Retrieved from http:/quanticfoundry.com/2015/12/15/handy-reference/

Yee, N., Ducheneaut, N., \& Nelson, L. (2012). Online Gaming Motivations Scale: Development and Validation. In Proceedings of the SIGCHI Conference on Human Factors in Computing Systems CHI '12 (pp. 2803-2806). http://doi.org/10.1145/2207676.2208681 


\section{AUTHORS' BIOGRAPHIES}

Gustavo Fortes Tondello, M.Sc., is working towards his Ph.D. at the Cheriton School of Computer Science, University of Waterloo, Canada. His main interests include gamification and games for health, wellbeing, and learning. His research investigates topics related to design, evaluation, and personalization of serious games and gameful applications. See blog.gamefulbits.com.

Dr. Deltcho Valtchanov is a postdoctoral researcher with a background in virtual reality, human visual perception, and cognitive and behavioural neuroscience. His projects focus on the gamification of digital archives and in exploring how visual processing of scenes and user interfaces may influence the esthetics and coherence of interactive media.

Dr. Adrian Reetz is working as a postdoctoral researcher at the Games Institute at University of Waterloo. He researches the effectiveness of games on people's engagement with meditation and mindfulness exercises. Other research interests include exploiting cognitive disconnect in virtual realities and measuring the effect of stressors on motor performance.

Rina R. Wehbe, M.Sc., is working towards her Ph.D. at the Cheriton School of Computer Science and coaffiliated with the Games Institute at University of Waterloo. Her research focuses on error feedback for the novice and expert user. Other interests include games for health, social and affective computing. See rinawehbe.com.

Dr. Rita Orji is an Assistant Professor at Dalhousie University, Canada. Previously, she was a Banting Postdoctoral Fellow at the University of Waterloo, Canada. Her research includes personalization, user modeling, persuasive technologies, and games for change. She is passionate about investigating mechanisms for designing persuasive games to increase their effectiveness.

Dr. Lennart E. Nacke is an Associate Professor for Human-Computer Interaction and Game Design at the University of Waterloo. He investigates cognitive and emotional aspects of video games to understand their effects. Dr. Nacke designs, researches, and develops gameful and motivating software to improve people's physical fitness and mental wellbeing. 